\title{
Prediction of Rail Damage Using a Combination of Shakedown Map and Wheel-Rail Contact Energy
}

\section{Pelin BOYACIOGLU ${ }^{\mathrm{a}, *}$ and Adam BEVAN ${ }^{\mathrm{b}}$}

\author{
${ }^{\text {a }}$ Ricardo Rail, 30 Eastbourne Terrace, London, W2 6LA, UK \\ ${ }^{\mathrm{b}}$ Institute of Railway Research, School of Computing and Engineering, University of Huddersfield, \\ Huddersfield, HD1 3DH, UK
}

* Corresponding Author e-mail; pelin.boyacioglu@ ricardo.com

\begin{abstract}
Rolling contact fatigue and wear are two key damage mechanisms that govern rail life. Although there are several different mechanisms affecting both their initiation and propagation, the trade-off between them is important and their accurate predictions can provide significant benefits when planning rail maintenance activities. Through integration with vehicle dynamics simulations, damage models based on the wheel-rail contact energy ( $\mathrm{T} \gamma$ ) and Shakedown theory have often been used to predict damage. In this paper, the findings from previous studies are reviewed to identify their limitations. To assess the accuracy of the predictions, their input parameters were compared for sites with and without reported RCF defects from two lines on the London Underground network. The results indicated certain variations and hence, a new wear and RCF damage prediction method was developed using a combined Shakedown Map and T $\gamma$ approach. While the wear model predictions were validated by comparison with measured rail wear, the availability of field crack depth measurements enabled the validation of the new RCF crack depth prediction model. Reasonable predictions of crack depth and wear over consecutive intervals have been achieved on various sites which increases the confidence of the models to support future optimisation of maintenance planning.
\end{abstract}

Keywords: rolling contact fatigue; wear modelling; contact mechanics; vehicle dynamics modelling

\section{Introduction}

When rails are exposed to successive wheel passages, RCF cracks are initiated due to high plastic deformation accumulations under cyclic loading. After initiation, their propagation is mainly driven by the stresses (bending and shear) generated during successive wheel passages [1]. There are several factors influencing both the initiation and propagation phases of RCF cracks which stem from material characteristics, operational and environmental conditions such as the effect of fluids, lubricants and water.

Additionally, high wheel-rail contact stresses can cause wear damage on the rail surface. Although different types of wear mechanisms such as oxidative, adhesive and abrasive wear can occur between the wheel and rail, high levels of plastic flow can also contribute to both RCF cracking and (delamination) wear [2]. Under this condition, the initial stages of both damage types are very similar, but interact with each other in a highly complex manner. Laboratory and field investigations indicate that in some cases wear can dominate resulting in the removal of initiated cracks; however in other cases the wear rate can be low allowing the cracks to propagate [3]. Therefore, to accurately predict the crack growth rate, the interaction between wear and RCF should be considered.

To predict both of the damage types, various models have been developed using different methods. For instance, crack growth models using fracture mechanics mainly investigate the changes in stress levels under different factors, particularly the effect of fluid [4-7]. On the other hand, crack initiation models often used multi-axial fatigue criterion $[8,9]$ such as the subsurface fatigue index $\left(\mathrm{FI}_{\text {sub }}\right)$ which considered the cracks initiated at about $3 \mathrm{~mm}$ below the surface [10]. In addition, there are also material 
based approaches. For example, [11] showed the influence of anisotropy; cracks grew parallel to aligned lamellae generated under plastic deformation and the approximate wear and damage (AWD) model demonstrated that (microscopic) cracks either lead to the formation of flakes or wedge-like structures depending on the distribution of angular plastic shear strain; whereas flakes can lead to wear, wedge like structures can contribute wear and/or RCF which can ultimately form macroscopic fatigue cracks [12]. The AWD model was later used in combination with the extended creep force (ECF) model to form an overall wheel-rail damage (OCD) model [13].

Furthermore, there are other models based on the Shakedown Map theory [14], related ratchetting failure [15] and wheel-rail contact energy (T $\gamma$ ) based models which were both used to predict RCF; Whole Life Rail Model (WLRM) [16] and wear; BRR function [17] as well as models which use T $\gamma / \mathrm{A}$ [18].

To support maintenance planning of entire networks, damage should be predicted over long distances considering a wide range of operational conditions, e.g. changing traffic, track geometry characteristics and wheel-rail profiles. Some of the above models provide detailed analysis, often using finite element (FE) modelling which requires high computational times to solve a number of cases. Therefore, this modelling technique becomes impractical to apply and more rapid approaches are necessary which can be easily integrated with vehicle dynamics simulations to calculate wheel-rail contact conditions for various operating environments.

Owing to this requirement, the T $\gamma$ and Shakedown Map based models have been commonly used in the previous studies $[16,19,20]$. But, while they provided good indications for sites susceptible to rail damage, certain deficiencies have been also demonstrated. In this paper, these models are reviewed along with assumptions and relevant findings from previous studies. The results of the initial application of the models on the London Underground (LUL) network showed that they over- and- under estimated the damage under certain circumstances. In order to find an optimum solution, the main input parameters such as $\mathrm{T} \gamma$, maximum contact stress $\left(\mathrm{P}_{0}\right)$, traction coefficient $(\mathrm{T} / \mathrm{N})$ and creep force angle $(\theta)$ were compared for sites with and without reported RCF defects. The parameters showed variations between different sites and highlighted areas for further consideration.

As a consequence, new wear and RCF damage models were developed which utilise a combination of the Shakedown Map and T $\gamma$ approach. As the crack depth is a key parameter in severity assessment and maintenance (grinding) planning, LUL has employed a magnetic flux leakage based sensor, the MRX Rail Surface Crack Measurement (MRX-RSCM), to detect both surface and subsurface RCF damage. These measurements helped to develop and validate the new RCF crack depth prediction model while MiniProf measurements were used in the new wear method comparisons. The location and severity of both damage types were predicted on the selected RCF monitoring sites. Successive crack measurements provided opportunities to observe and predict changes in RCF damage propagation and its interaction with wear over time. Therefore, this novel use of field data allowed to improve the accuracy of the damage predictions at several sites with various track and operational characteristics. This may potentially help to support maintenance planning and to move towards a condition-based maintenance regime. 


\section{Methodology - Rail Damage Predictions Models}

\subsection{T $\gamma$ based models}

\subsubsection{T $\gamma$ based models - in RCF Predictions}

$\mathrm{T} \gamma$ is commonly used in both wear and RCF damage predictions. It is the energy produced at the wheelrail contact and calculated from the sum of the products of the creepage and creep forces as defined in equation below:

$$
T \gamma=T_{x} \gamma_{x}+T_{y} \gamma_{y}+M_{z} w_{z}
$$

where $T_{x}, T_{y}$ and $\gamma_{x}, \gamma_{y}$ are the tangential creep forces and the corresponding creepages in the longitudinal and lateral directions respectively, and $M_{z}$ and $w_{z}$ are the spin moment and the corresponding spin creepage respectively [21].

Even though the parameter was initially used to predict wear, it was later proposed that the energy dissipated in the contact patch could also result in RCF damage. After several revisions, the WLRM RCF Damage Function was developed as shown in Figure 1. In addition to predicting RCF damage, the model estimates the interaction of wear which may remove RCF defects. It is assumed that the fatigue initiates at $15 \mathrm{~N}(\mathrm{~J} / \mathrm{m})$ and reaches its peak at $65 \mathrm{~N}$. After this limit, the wear risk increases and becomes equal to RCF at $175 \mathrm{~N}$, but it dominates with the further increase in $\mathrm{T} \gamma$ levels $(>175 \mathrm{~N})$.

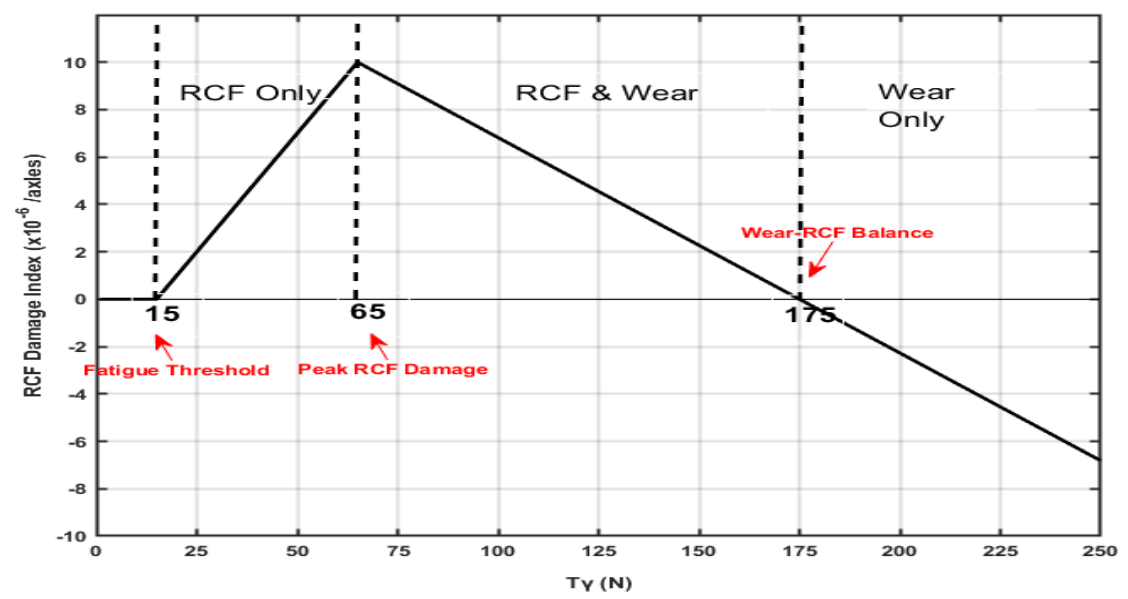

Figure 1: WLRM RCF damage function (16)

The original WLRM damage function was developed through empirical techniques to predict the initiation and location of RCF cracks by comparing observed RCF locations and severity at a number of sites with the predicted levels of $\mathrm{T} \gamma$. Therefore, it mainly describes the performance of the rail steel grade at these site (e.g. R260) against a variety of wheel profile shapes (e.g. P8) and wheel steel grades (e.g. R8T) operated on the Great Britain (GB) mixed traffic railway. For each contact point, the RCF damage function translates the energy into an increment of fatigue damage. The incremental damage from axle passages are accumulated and when the damage index reaches 1, the model predicts the formation of a crack. However, the model contains certain assumptions as summarised below:

a) 'Signed $\mathrm{T} \gamma$ ' assumption: $\mathrm{T} \gamma$ in the WLRM is referred to as 'signed $\mathrm{T} \gamma$ ' which is the raw $\mathrm{T} \gamma$ signed by the direction of the longitudinal creep force. It was based on the assumption that RCF in rails is driven by forces in the traction direction. Since the previous crack growth modelling studies showed that cracks could propagate by the fluid (entrapment) effect under traction direction, the model only considers the regions where the longitudinal force on the rail is opposite to the direction of travel [22]. However, previous studies which compared the model results with field observations stated that whilst 
it produced good validation results on high (outer) rail of curved tracks, it often disregarded the low (inner) rail cracking. It was later suggested that creep forces in different directions may also drive RCF cracking [21, 23].

b) Performance of the model in different railway networks: Whereas it was primarily used and validated on GB mainline route tracks, it was not applied on different system such as metrounderground and heavy-haul lines.

c) Wheel-rail friction levels: Due to uncertainties in the actual friction levels on track and to ensure the worst case forces were predicted, the WLRM was developed using a high coefficient of friction ( $\mu$ $=0.45$ ). In reality, sites will often have a coefficient of friction which is lower than 0.45 and this will vary significantly over the life of the rail (due to environmental conditions and/or the presence of third body layers such as lubrication) which in turn will influence the energy dissipated at the wheel-rail contact and RCF development, as well as promote different wear mechanisms in rails.

d) Rail steel grade: The model was developed based on the performance of a standard R260 rail material. In relation to different steel grades, new damage functions have been proposed based on their material properties and performances during twin-disc testing and under site conditions [21, 24]. The validation of these models is still ongoing, however a recent study found good agreement with field observations when predicting the higher resistance to RCF initiation of R370CrHT steel grade using a modified damage function [25].

e) Prediction of crack depth: The model has provided relatively good correlation with actual RCF conditions seen on sites, such as location, density and surface length of cracking. But, it has not been validated using crack depth which is a critical parameter in the assessment of the crack severity and for planning future maintenance activities (e.g. rail grinding). Due to the effect of several factors and changing contact conditions experienced by rails in different operating environments, the previous investigations revealed no direct correlation between surface length and crack depth [26, 27].

\subsection{2. $\mathrm{T} \gamma$ based models - in Wear predictions}

T $\gamma$ was initially used for the prediction of wear damage and a number of studies were performed which included laboratory testing and field measurements to provide a relationship between $\mathrm{T} \gamma$ and wear rate [28]. Figure 2 shows the British Rail Research (BRR) function which displays the mild, transitional and severe wear rates by the increase in T $\gamma$ levels under full-scale testing of the BS11 (rail) and R8 wheel materials. Contrary to the WLRM, this model uses the 'raw $\mathrm{T} \gamma$ ' and therefore, considers the energy generated at all contacts, regardless of the direction of the creep forces.

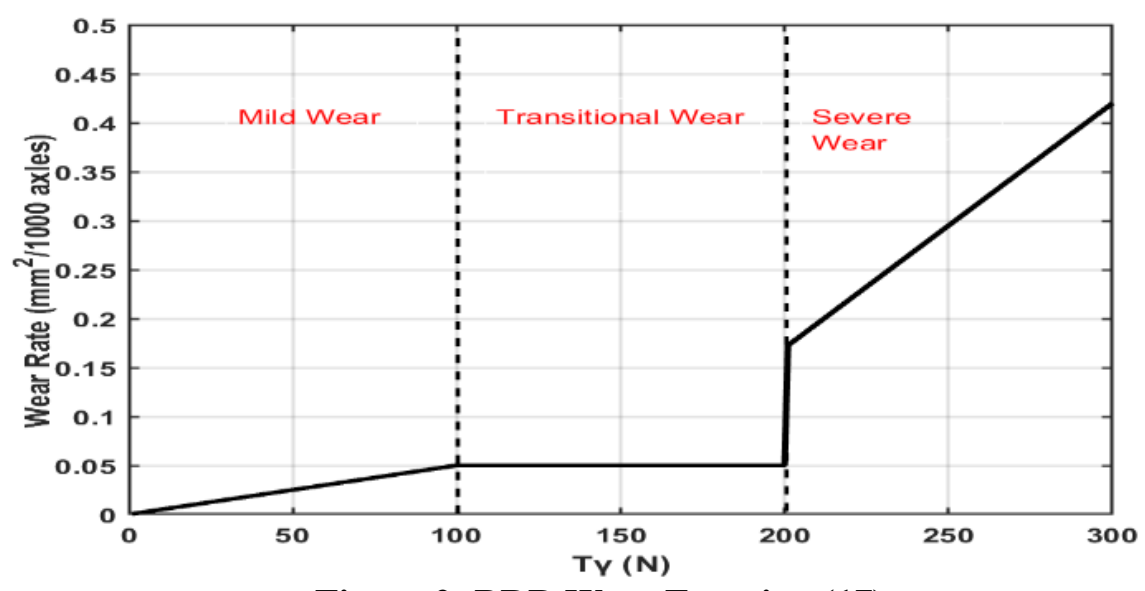

Figure 2: BRR Wear Function (17) 
Subsequently, several laboratory experiments were conducted and the BRR function was adapted to include the parameter $\mathrm{T} \gamma / \mathrm{A}$. It was found that creep force, creepage and Hertzian contact area (A) were the main influencing parameters and three wear regimes were identified: mild, severe and catastrophic in the metallurgical investigations [18]. Furthermore, it was stated that while the T $\gamma$ method helped to show the transitions in wear rates and could reflect the changes of other contact parameters such as pressure and slip by moving the values on the wear curve, it did not demonstrate their individual contributions on wear [29]. The mapping method with the Archard's function was later employed [30]. Although both of these models rely on establishing wear coefficients found from laboratory (e.g. pinon-disc and/or twin-disc) testing under mainly dry conditions, they are frequently applied in real-track cases. To compare wear rates (as well as different mechanisms) under water, grease lubricated and dry conditions, twin-discs tests were carried out [31]. As it can be seen from Figure 3, the wear rates are considerably lower and larger slips are required to achieve similar energy levels compared to dry case.

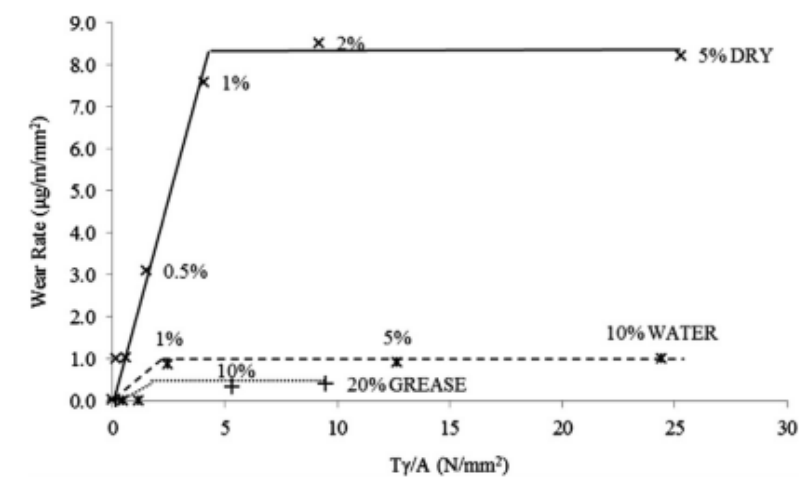

Figure 3: Wear rates at low T $\gamma / A$ values under dry, water and grease lubricated conditions for R260 rail against $R 8 T$ wheel material (31)

\subsection{Shakedown Map}

The Shakedown Map was developed to define the material's response to wheel-rail contact under different loading conditions [32]. As the contact stress increases, the rate of plastic deformation accumulation also increases from elastic shakedown to plastic shakedown. Whereas the material is expected to fail by high cycle fatigue (HCF) in the former, an earlier failure occurs in the latter by low cycle fatigue (LCF). In the ratchetting region, critical loading conditions lead to (uni-directional) incremental growth by every load passage. These different failure mechanisms were mainly associated with RCF cracking where site observations showed that ratchetting caused earlier crack initiation than LCF and HCF produced no visual cracking [33]. Figure 4 displays the limits of these different responses for rolling-sliding point (circular) contact. These limits were initially computed for line contact [34] and it should be noted that wear (mechanisms) was not considered in the model development.

When the maximum contact stress is higher than the shear yield limit (k), hardening and residual stresses are introduced, increasing the material resistance in the following limits. Whereas y-axis is the load factor which represented by $\lambda \mathrm{P}_{0} / \mathrm{k}$ ( $\lambda$ is the shape factor), the $\mathrm{x}$-axis is the traction coefficient represented as $\mathrm{f}, \mu$ or $\mathrm{T} / \mathrm{N}$ in the literature.

$$
\lambda P_{0} /_{k}=\frac{3 F_{N}}{2 \pi a b k} \quad f=\mu=\frac{T}{N}=\sqrt{{F_{y}{ }^{2}+F_{x}^{2}}^{2}} F_{N}
$$

where $\mathrm{F}_{\mathrm{y}}$ and $\mathrm{F}_{\mathrm{x}}$ are the lateral and longitudinal tangential forces $(\mathrm{N}), F_{N}$ is the normal load $(\mathrm{N})$ and a, $\mathrm{b}(\mathrm{mm})$ are the semi-axes of the wheel-rail contact patch. When the traction coefficient was lower than 
$\sim 0.3$, yield initiated at the subsurface, while the exceedance of this limit initiated surface plastic flow. This limit is indicated as 0.25 in Shakedown Map for line contact.

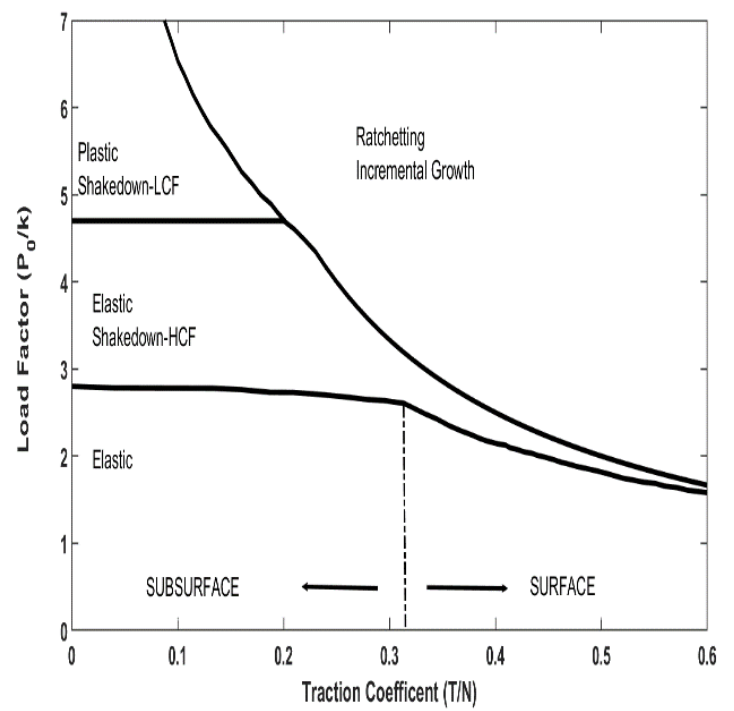

Figure 4: Shakedown Map for (circular) point contacts (32)

The model's assumptions are as follows:

a) Hertzian contact theory: The model was developed based on Hertzian theory, although it has certain assumptions [35], the model extended this by including the inelastic material response and rolling friction [33].

b) Under Partial-Slip: While both rolling and full slip contacts were considered, the partial-slip condition, meaning a lower traction coefficient $(\mathrm{T} / \mathrm{N})$ than the friction $\mu$, was mainly neglected. The study which investigated the effect of partial slip showed that while it had lesser influence on subsurface stresses (under low friction), the maximum principal shear stress was increased and in turn, reduced the Shakedown limit under high friction. This may potentially make a partial slip contact more damaging than full slip contact [36]. Nevertheless, it was also stated a partial slip condition may have larger influence on line contacts than point contacts.

c) Effect of Different $(\lambda)$ levels: It was stated that the Shakedown Map was applicable for particularly point contacts which have larger lateral width than its longitudinal semi axis $(b \geq a)$ and circular contact $(\mathrm{a}=\mathrm{b})$. The study which analysed the effect of different ellipticity levels $(\mathrm{a} / \mathrm{b})$ on the ratchetting limit found that the limit monotonically decreased with different b/a levels, but they became almost similar at $\mu=0.4$ [37].

\section{Limitations in using the prediction models on underground-metro systems}

\subsection{Previous applications, results and gaps}

The Surface Fatigue Index ( $\left.\mathrm{FI}_{\text {surf }}\right)$ [38] calculated from the horizontal projection of the shortest distance between contact points and the ratchetting limit predicted the RCF for all the twin-disc and full-scale experiments with the exception of wet twin-disc cases in which the $\left(\mathrm{FI}_{\text {surf }}\right)$ value was given as negative (lower than the ratchetting limit) due to lower friction coefficient. But, it was noticed that although the higher $\mathrm{FI}_{\text {surf }}$ values led to early crack initiation, wear removed these initiated cracks [39].

Several studies compared the $\mathrm{FI}_{\text {surf }}$ and WLRM predictions and found that the WLRM damage index provided a better correlation to field observations than the $\mathrm{FI}_{\text {surf }}$ which underestimated some of the damage [40]. In tighter curves, the damage index became negative showing the larger wear rate over 
crack initiation, but in these areas, the $\mathrm{FI}_{\text {surf, }}$ had the highest values (more distant to ratchetting limit). It was later stated that although the $\mathrm{FI}_{\text {surf }}$ might underestimate the RCF prediction for high creepages, due to limitation of traction coefficient values by the maximum friction coefficient, the damage index might overestimate, as the increased creepages did not influence RCF life in the laboratory experiments [36].

In relation to third body materials, the twin disc data under dry, water and grease tests were overlaid to the Shakedown Map [31]. Whereas the dry case fell within the ratchetting region in which high plastic deformations and wear were observed, the water and grease lubricated conditions were predicted to be in the elastic shakedown region, resulting in lower levels of plastic deformation compared to dry case.

Work hardening increases the shear yield limit on the surface, but it was observed that it decreased and became constant after reaching certain depth [41]. It was shown that the friction coefficient played an important role in the work hardening and its further effect on shakedown limit. Under $\mu=0.1$, the maximum shear yield limit occurred at $0.45 \mathrm{a}$ depth and increased the shakedown limit considerably while, under $\mu=0.5$, the maximum shear yield limit occurred at the surface with a relatively lower influence on the shakedown limit.

\subsection{Application of the models to London Underground}

Research has been conducted to investigate the rail damage mechanisms on selected lines of LUL [42]. Some of the initial related work can be also found in $[43,44]$. To model the Bakerloo (BAK) and Jubilee (JUB) lines, detailed route simulations were developed using the vehicle dynamic simulation software, Vampire. The vehicle models of the 72TS-Tube Stock (BAK) and 96TS (JUB) were used with the track model consisting of vehicle speed profiles, geometrical irregularities from track recording vehicle data outputs and additional traction/braking forces. In addition, the effect of track and on-vehicle (stick lubes) lubrication were considered through a reduction in the wheel-rail friction coefficient. Typical values of $\mu=0.15$ (flange; under lubricated regions) and $\mu=0.36$ (tread; tunnel sections) were selected which agreed with measurements from similar system and previous simulation studies $[45,46]$.

To describe the changes in contact conditions, variations in new and worn wheel-rail profiles were considered. Worn rail profiles were measured at certain distance intervals along the lines, including the use of both bullhead (BH:BS951b) and flat-bottom (FB:CEN 56E1) rail types. In respect to wheels, LT3 (BAK) and LT5 (JUB) wheels with the three different worn levels; lightly, moderately and severely worn wheels were selected based on the distribution of a large variety of flange height and thickness measurements. All of these variations represented in both the contact calculations and the track models help to describe the changes experienced in real track operations. Changes in the contact parameters and damage model input parameters, such as $\mathrm{T} \gamma, \mathrm{T} / \mathrm{N}$ and $\mathrm{P}_{0} / \mathrm{k}$, were outputs from the route simulations. The shear yield limit was taken as $400 \mathrm{MPa}$ for the R260 steel grade rails. Based on the aforementioned study (41), it may be expected that the strain hardening can lead to an increase, but as the rail wears, the values can alter which can affect the shakedown limit differently under various friction conditions.

In [43], the applicability of the WLRM for use on studied metro lines was investigated and compared with the predictions on a GB mainline route; Midland (MML) mainline. Firstly, the influence of parameters: curve radius, friction coefficient, track irregularities, wheel/rail profiles on the resulting 'signed $\mathrm{T} \gamma$ ' values were examined between flange and tread contacts on high rail and single low rail contacts. Similar to previous WLRM studies $[19,21]$, the values were mainly larger at flange contacts of MML due to the consideration of only traction direction. However, the infrastructure characteristics and additional traction forces in the start-stop nature of metro system operations influenced the level of 'signed $\mathrm{T} \gamma$ ', resulting in the high rail tread and low rail contacts being also susceptible to damage on the LUL. For instance, whereas the decrease in curve radius particularly increased the energy results, the decrease in the friction coefficient through the application of lubrication caused a reduction in the 
energy levels, resulting in higher RCF than wear damage risks. Secondly, the relationship between the T $\gamma$ and the Shakedown Map was also investigated. For the three different contacts, special Shakedown Map plots were prepared in which the corresponding $T \gamma$ values were also indicated. It was noticed that particularly at single low rail contacts that the larger patch areas led to a reduction in the contact stresses and hence, the majority of contact points on BAK and JUB did not exceed the limit lines. By contrast, the elimination of contacts in the braking direction especially in the MML led to mainly zero 'signed $\mathrm{T} \gamma$ ' with no predicted damage risks, but the 'raw $T \gamma$ ' values particularly for curves $1500 \mathrm{~m}<\mathrm{R}<1750 \mathrm{~m}$ showed that although they had lower energy, the heavier axle loads gave rise to contact stresses which resulted in ratchetting failure according to the Shakedown Map.

A subsequent study [44] presented correlations of 'signed T $\gamma$ ' values with the NDT crack depth locations. At several locations along the lines, the high values showed good agreement with measured cracking. Nevertheless, some values produced overestimations, as there were no defects, particularly on high rails. Additionally, the zero values (braking direction) resulted in underestimation which was particularly observed on the low rail of curved tracks.

Therefore, previous studies conducted both in the literature and for LUL demonstrated that the models had certain deficiencies. In order to find an optimum solution between the over- and under- estimations, the track characteristics and the key areas leading to inaccurate predictions were identified as shown in Figure 5. Even though the high T $\gamma$ values may lead to overestimation in the prediction of RCF damage, they may also give rise to excessive wear rates which in turn may remove the initiated cracks. Thus, the effect of wear on crack development should be taken into account. On the other hand, the underestimations might be caused by two possible reasons. Firstly, the method of signing T $\gamma$ limited the model to consider only traction regions and hence, the braking regions were neglected. Secondly, the contact energy parameter might not be sufficient to describe the overall changes at the wheel-rail contact. As previously described in the Shakedown Map comparison plots, the contacts which had lower 'raw $\mathrm{T} \gamma$ ' values had greater contact stresses. Therefore, the research suggested that variations in the input parameters; (raw) $\mathrm{T} \gamma$, maximum contact stress $\left(\mathrm{P}_{0}\right)$, traction coefficient $(\mathrm{T} / \mathrm{N})$ and creep force angle $(\theta)$ should be compared between the sites having reported and no reported defects.

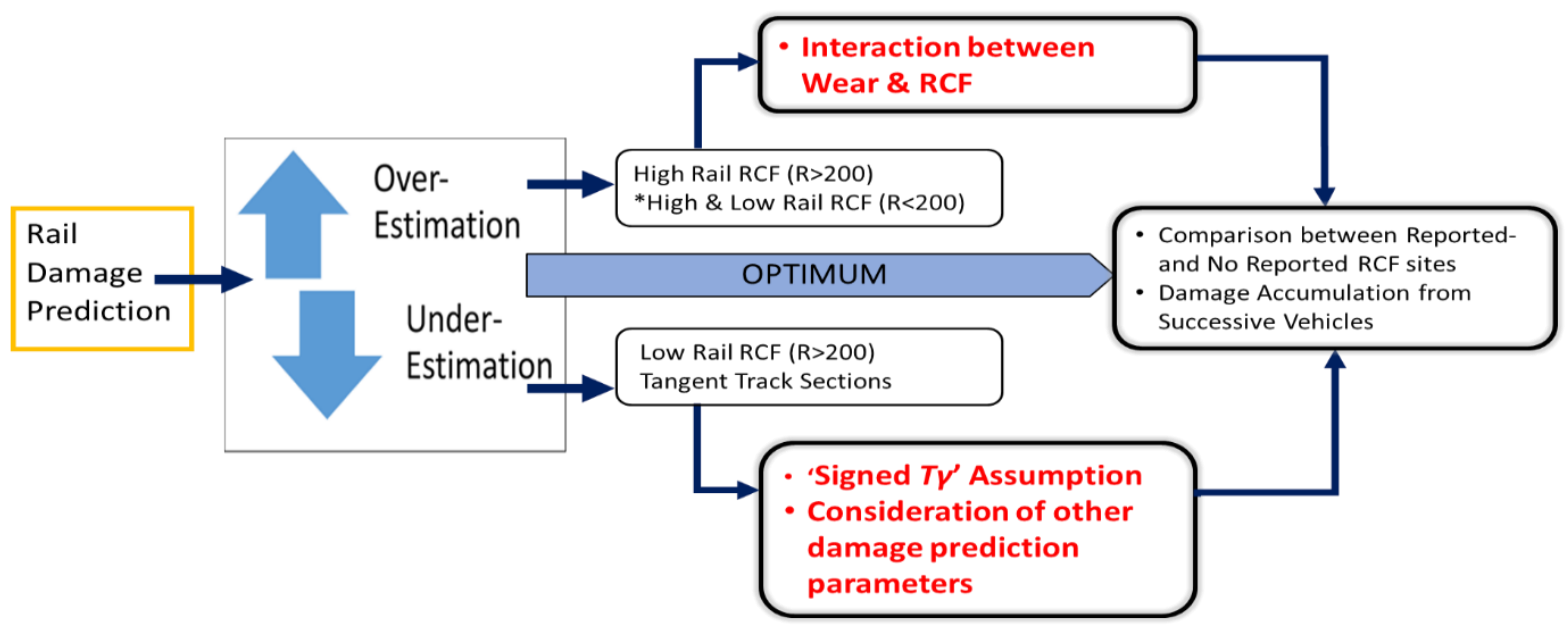

Figure 5: Potential reasons for over- and under estimations and suggestions to find the optimum solution

\subsection{Comparison of models' parameters between reported and no reported RCF sites}

To include changes in tracks with a variety of characteristics, sites were selected from three different groups: curved $(\mathrm{R}>200 \mathrm{~m})$, checked curves $(\mathrm{R}<200 \mathrm{~m})$ and tangent tracks. Fifty meter-long sites were selected from the defect data sheets of Bakerloo and Jubilee lines in the reported sites, and sites with 
equal distances and similar operating and track conditions, but having no reported defects, were identified. Rail grade of R260 was used in all these sites.

Figure 6 shows the changes in $\mathrm{T} / \mathrm{N}$ and $\mathrm{P}_{0}$ from all the contacts on different selected sites computed using Vampire, with the blue colour showing the reported RCF sites and the red colour indicates the no reported RCF sites. Additionally, each marker style represents different contacts on the rails. As expected, the contacts produced various results, but it can be clearly seen that the majority of (83\%) contacts on reported RCF sites are located inside the indicated boundaries while a large portion (67\%) of contacts from the no reported RCF sites are located either above or below these boundaries.

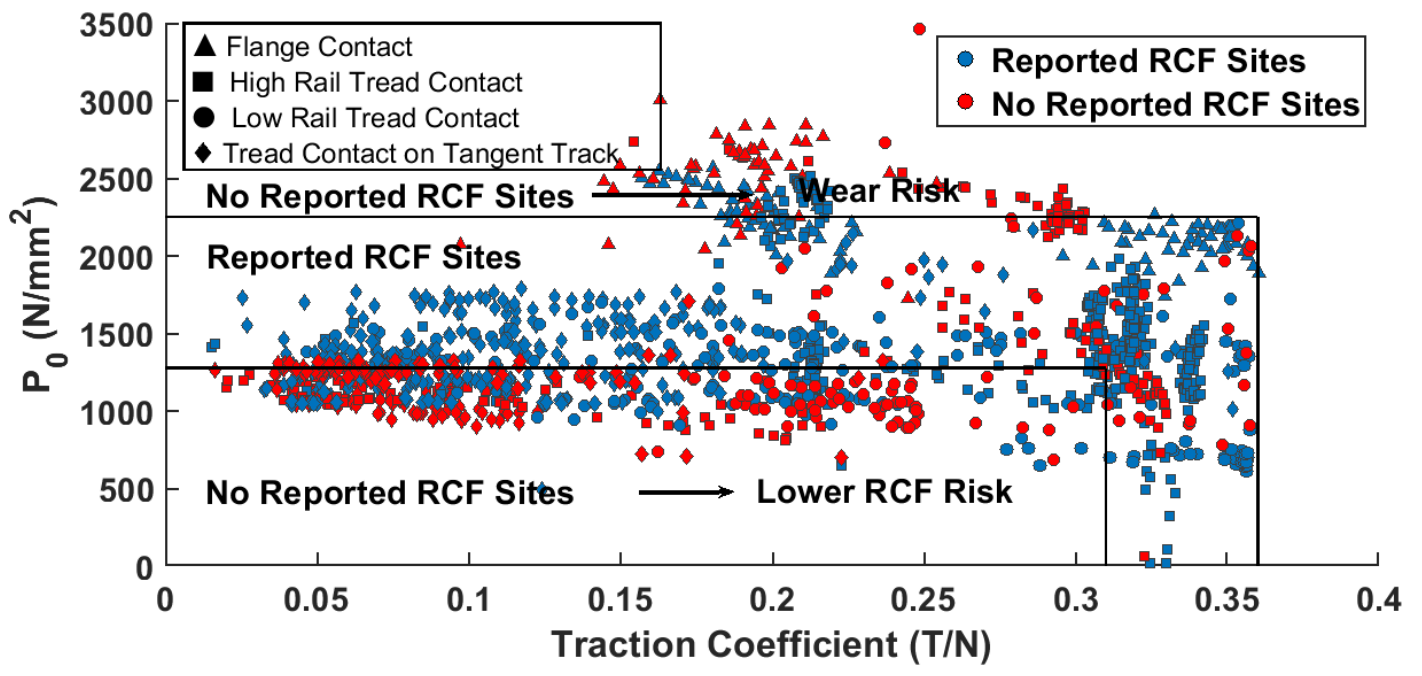

Figure 6: T/N against $P_{0}$ for different contacts on the selected reported and no reported RCF sites

Additionally, to observe the changes in $T \gamma$ values and creep force angle $(\theta)$ for each presented contact at selected sites, Figures 7 and 8 were developed. For the ease of presentation, the $T \gamma$ ranges were given based on different risk levels of the WLRM damage index and represented by different colours in Figure 7. Similarly, the creep force angles which are found from the angle between longitudinal $\left(F_{x}\right)$ and lateral creep forces $\left(\mathrm{F}_{\mathrm{y}}\right)$ were presented based on their quadrants (regions) in Figure 8. Since the traction direction on the rail corresponds to positive longitudinal creep force on the wheel, the regions (I: $0^{\circ}$ $90^{\circ}$ ) and (IV:270 -360$)$ show the traction direction and regions (II: $\left.90^{\circ}-180^{\circ}\right)$ and (III: $\left.180^{\circ}-270^{\circ}\right)$ demonstrate the braking direction. 


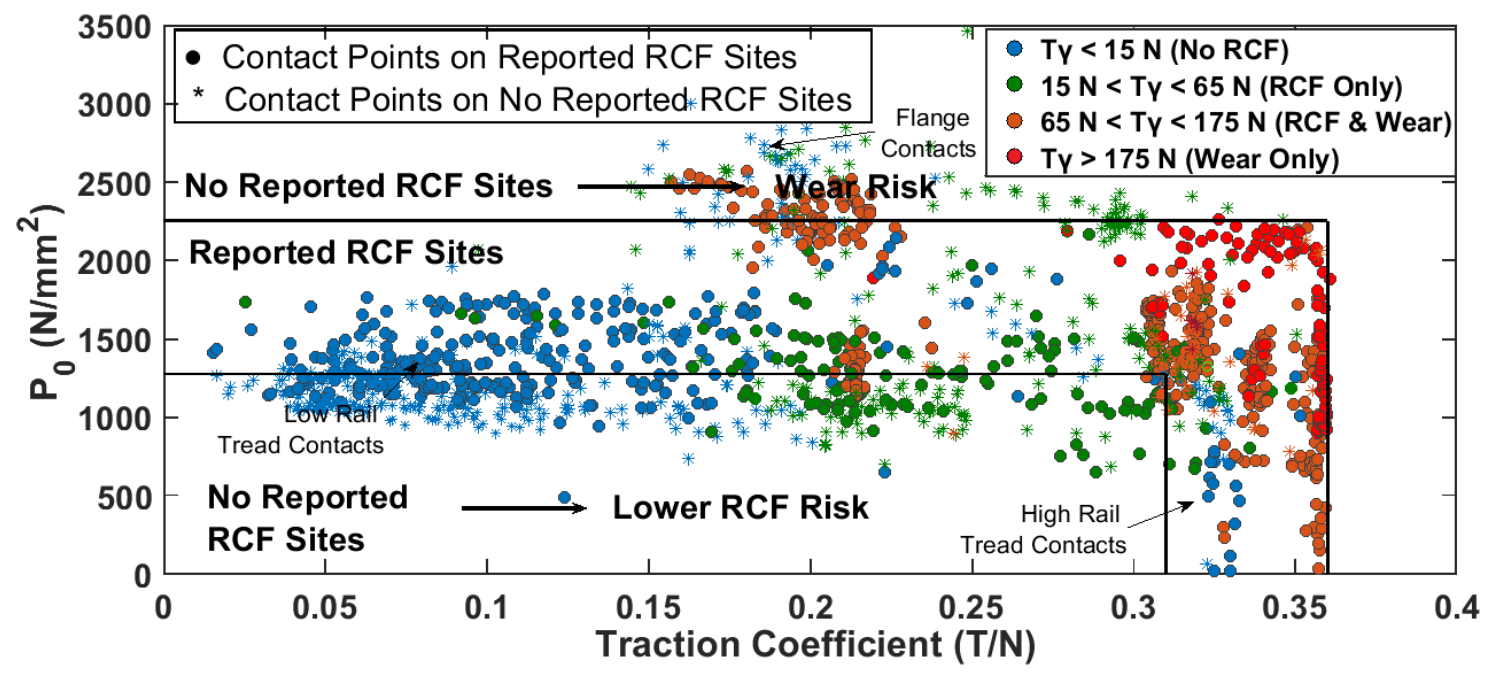

Figure 7: T/N against $P_{0}$ and the corresponding $T \gamma$ ranges for different contacts on the selected reported and no reported RCF sites

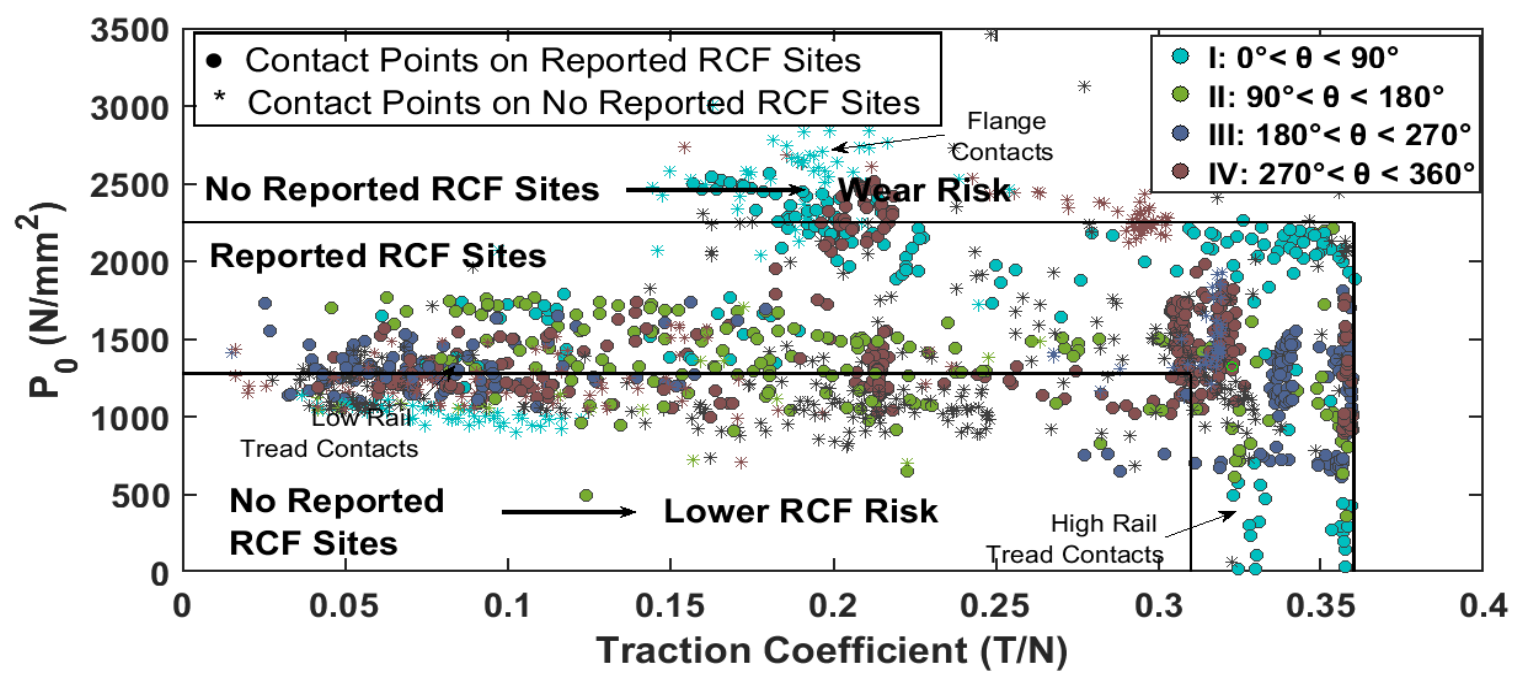

Figure 8: T/N against $P_{0}$ and the creep force angle regions for different contacts on the selected reported and no reported $\mathrm{RCF}$ sites

When the values between with reported and no reported sites were compared, the study concluded the following results regarding the four key parameters considered in the analysis:

1. Traction Coefficient $(\mathrm{T} / \mathrm{N})$ :

- Due to limitation of $\mathrm{T} / \mathrm{N}$ by the friction coefficient, the values could not exceed the maximum frictions coefficients $\mu=0.25$ (overground) and $\mu=0.36$ (underground) in the simulations. However, when the values in each track category were analysed, it was noticed that whereas the T/N of 0.31 seemed to be critical particularly for the curved track sites in underground sections, the T/N of 0.25 was also significant for overground and tangent track sections. As the previous studies pointed out that these specified limits are the transition region from subsurface to surface damage in the Shakedown Map for line and point contacts, the research suggested to further consider them in the rail damage predictions.

2. Maximum Contact Stress $\left(\mathrm{P}_{0}\right)$ : 
- It was apparent that a group of contacts on without reported sites generated higher $\mathrm{P}_{0}$ (Figure 6) which potentially suggests that the wear rate on these sites might exceed the crack growth rate and hence, the initiated cracks are removed by wear. But, it was also noted that some of the flange contacts have relatively low $T \gamma$ levels $<15 \mathrm{~N}$. Therefore, while the interaction of wear in the WLRM is described for the values having 'signed $\mathrm{T} \gamma$ ' $>65 \mathrm{~N}$, the lower energy values with higher $\mathrm{P}_{0}$ can also contribute to wear. Conversely, the reported sites mostly occurred between the defined upper and lower limits. But, when the $\mathrm{P}_{0}$ were less than the lower limit, the contacts were assumed to be less susceptible to damage.

3. Wheel-rail contact energy $(\mathrm{T} \gamma)$

- Whereas the predicted $\mathrm{T} \gamma$ ranges were raised by the increase in $\mathrm{T} / \mathrm{N}$ values, the $\mathrm{P}_{0}$ did not show a good correlation as the values varied for different contacts. However, it was noted that when the contacts exceeded the specified 0.25 and $0.31 \mathrm{~T} / \mathrm{N}$ limits, they showed RCF cracking regardless of low $\mathrm{T} \gamma$ values as can be seen from the high rail tread contacts on the reported RCF sites.

\section{Creep Force Angle $(\theta)$ :}

○ Creep force angles correlated with neither $\mathrm{T} / \mathrm{N}$ nor $\mathrm{P}_{0}$. In addition, they did not generally vary between reported and no reported RCF sites. It was noticed that they were primarily dependent on the position of the rails on the lines. Figure 8 showed that both flange and tread contacts on high (right) rails were often on the traction direction $\left(\mathrm{I}: 0^{\circ}-90^{\circ}\right.$ ) whereas, the braking directions (III: $180^{\circ}-270^{\circ}$ ) were usually occurred on the low rails. In respect to left rails, the opposite regions (IV:270 ${ }^{\circ}-360^{\circ}$ ) and (II: $90^{\circ}$ 180) were generated depending whether they were high and low side on curved tracks, respectively. The influence of check rails can be also seen, which modified the force directions on the Bakerloo line resulting in the low rails being in traction direction and high rails in braking direction.

\section{New RCF and Wear Damage Prediction Models}

The comparisons of contact parameters presented in the previous section illustrate the benefits of using both the Shakedown Map and T $\gamma$ for differentiating between damaging and non-damaging contacts. Since the Shakedown Map was less satisfactory for predicting the cumulative plastic deformation which takes place with successive rolling cycles, it is used to differentiate between the different damage types e.g. RCF and wear. Although it was mainly related with fatigue damage, some previous experiments demonstrated that ratchetting failure caused wear and removed initiated cracks $[3,39,47]$. Then, the $T \gamma$ value is used to quantify the severity of each damage type.

Whilst the results for the no reported sites in Figure 7 which had higher $\mathrm{P}_{0}$ with various $\mathrm{T} \gamma$ levels were taken into account in the wear damage predictions, the results of the reported sites which had the moderate $\mathrm{P}_{0}$ with relatively higher $\mathrm{T} / \mathrm{N}$ and $\mathrm{T} \gamma$ levels were considered in the RCF predictions. The previous studies which investigated the mechanisms causing different damage types demonstrated that although higher normal loads generated plastic deformations with relatively thicker layers in rails and were responsible for wear damage, the higher traction/braking forces caused larger shear forces with thinner deformed layers which in turn resulted in RCF cracking [48]. Similarly, the damage comparison between high speed and heavy-haul lines showed that plastic deformation became critical with greater axle loads, increasing the wear volume in the freight routes, whereas higher shear forces increased RCF severity in high speed lines [49].

The iterative process displayed in Figure 9 was applied to define the regions of the Shakedown Map associated with wear and RCF damage. In relation to wear predictions, various (upper) $\mathrm{P}_{0} / \mathrm{k}$ and $\mathrm{T} / \mathrm{N}$ values were assigned. If the contact parameters were inside this selected region, the BRR function was applied and the results compared with rail MiniProf measurements. 
Subsequently, contacts outside this region were assigned for the RCF predictions. The significance of a $\mathrm{T} / \mathrm{N}=0.31$, as well as the lower and upper limits $0.25<\mathrm{T} / \mathrm{N}<0.36$, where shown to play a key role and their corresponding $T \gamma$ values were taken to define the new breaking points of the model. The results were compared with the MRX-RSCM crack depth measurements. When the differences between predictions and measurements in terms of both RCF and wear were relatively small, meaning that the optimum solutions were obtained considering the measurements collected at different tonnages and from various track sites, then the iterative process was ended. Figures 10 and 11 present the new wear and RCF crack depth prediction models, respectively.

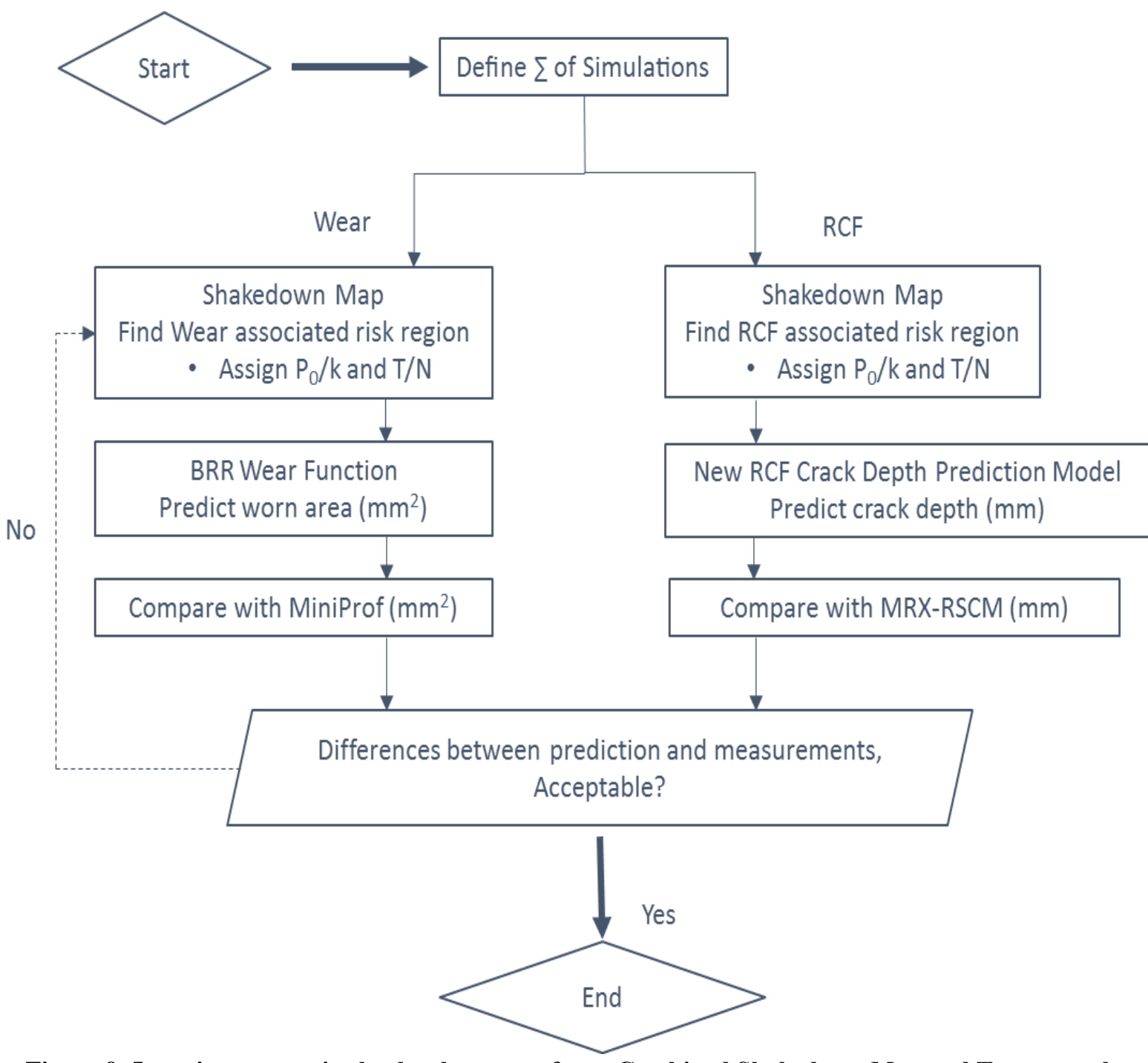

Figure 9: Iterative process in the development of new Combined Shakedown Map and T $\gamma$ approach 

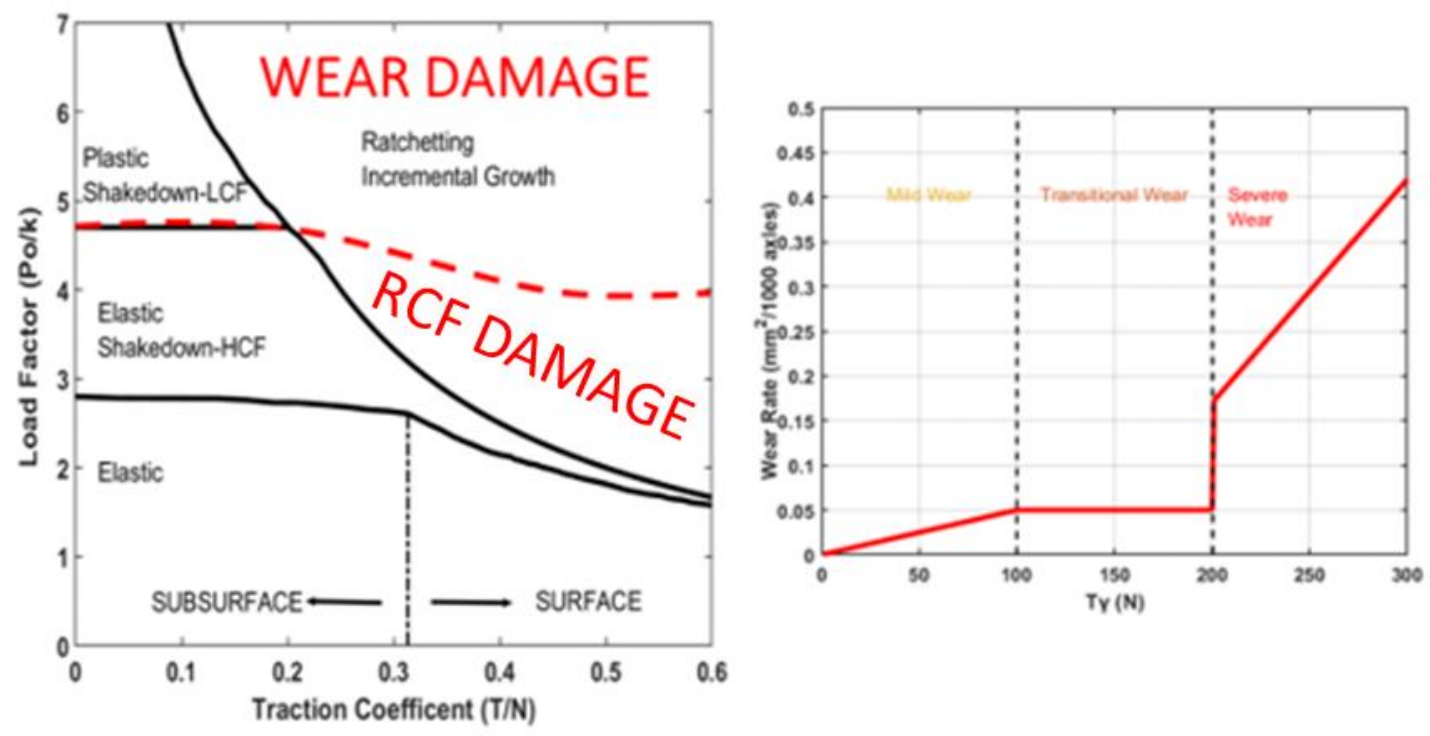

Figure 10: New wear prediction method

Even though the studied metro lines consist of different vehicle-track characteristics which result in different trends in the energy levels at the wheel-rail interface, the T $\gamma$ breaking points in this new RCF crack depth prediction model were identical to the WLRM. It was observed that while the smaller curve radius increased the $T \gamma$ substantially, the use of lower friction coefficients due to the application of lubrication decreased the energy values compared to using a relatively high friction coefficient of $\mu=0.45$ in the original WLRM. Additionally, the energy values in this model are the 'raw T $\gamma$ ' outputs and thus, they are not scaled by the direction of the creep forces and RCF damage is only calculated for contacts where their shakedown parameters fall inside the given damage regions defined in Figure 11. Furthermore, while the WLRM assumed the interaction of wear for higher T $\gamma$ values than $175 \mathrm{~N}$, the new model suggested an increased RCF risk under the associated region on the Shakedown Map.
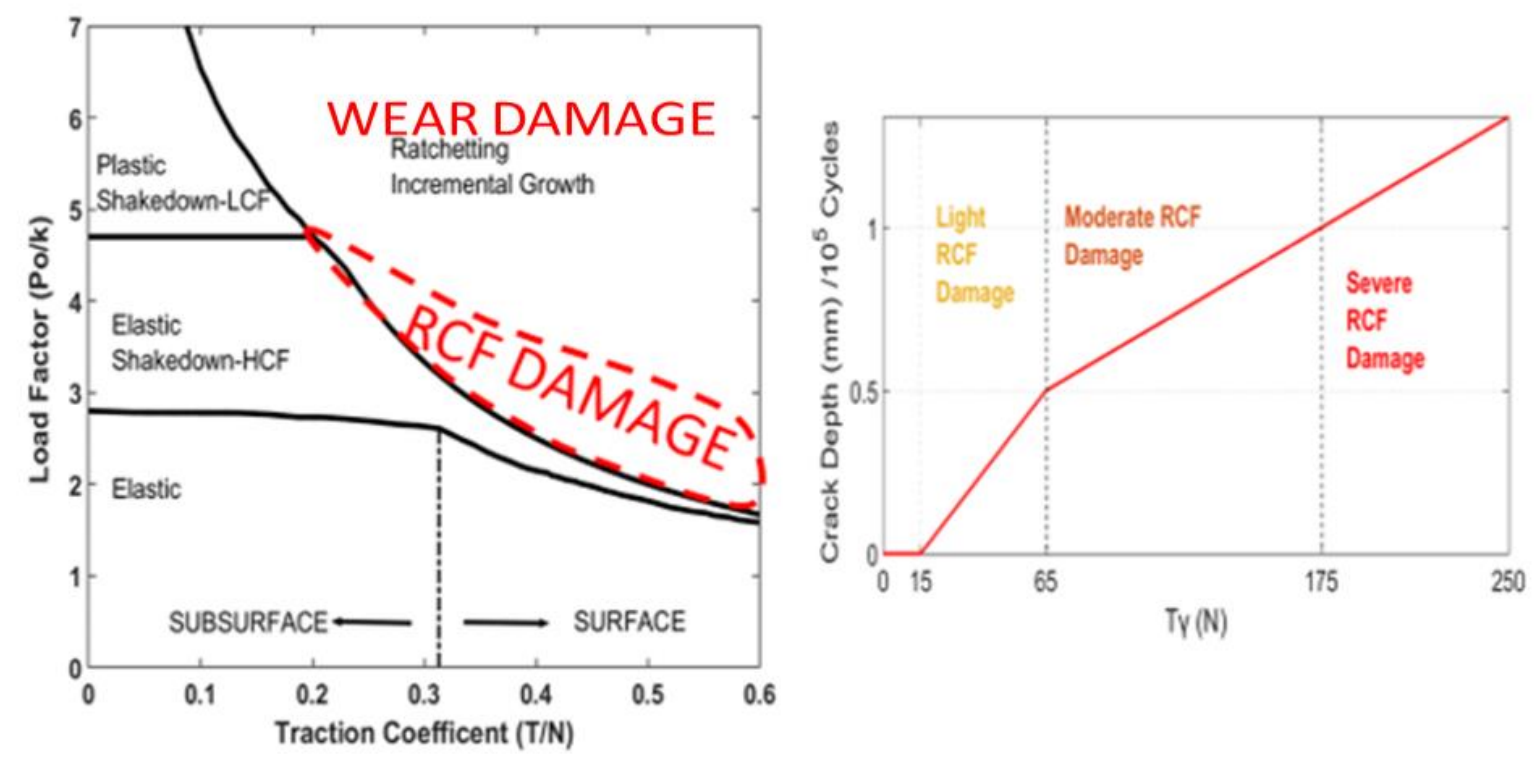

Figure 11: New RCF prediction method with the new crack depth prediction model 


\section{Rail damage prediction results, validations and discussions}

The new rail damage prediction methods were applied to the selected sites on LUL. These sites were recently re-railed due to RCF cracking, and the rail condition was inspected using MiniProf and MRXRSCM measurements at defined intervals to measure the level of wear and to detect the location and severity of defects.

The total number of vehicle passages were computed and the variations in contact conditions stemming from successive wheel passes were taken into account by using different wheel-rail profile combinations explained in the Section 3.2. Based on the duration between the inspection and rail installation dates, the damage predictions from these different simulations were accumulated in the study. However, it was noted during the initial predictions that they were considerably higher than the measurements. As it may be expected from the changes in different wear curves in Figure 3, the use of (dry) BRR function inevitably produced greater results in the real site conditions. In addition, all these different wear curves were developed using mainly twin-disc testing under defined number of cycles, but in reality, a variety of contact conditions occur over a million wheel passes under 10 (million gross tonnes) MGT on LUL. Thus, this also suggests that not all of the energy dissipated at wheel-rail contact translates into either RCF or wear damage, but translates into other mechanisms such as heat and plastic flow. As a result of the iterative process, a scaling factor was determined for the total number of wheel passages over a given location to generate realistic results. After a certain period (rail age), to represent the steady-state wear conditions occurred in testing [50], a further reduction was also applied.

\subsection{Wear predictions}

The new wear method predictions were compared with MiniProf measurements from these critical sites. To evaluate the models' performance under different conditions, the method was applied to sites with different track characteristics. Figures 12 and 13 display the measured material removal in terms of both depth (y-axis on the left) as well as area (hatched) which provides a comparison with the predicted worn area (y-axis on the right). The rails were located on the high transition (spiral) rail (350 m radius curve) and low rail (410 m radius curve), respectively. The peak values indicate the total accumulated predicted wear at the measured location.

It can be seen that good agreement was obtained in terms of both the lateral position across the railhead and magnitude of the total worn area. Despite the similar tonnage levels (300 days after the rail installation) on both of the sites, the model could demonstrate the changes for example, larger material removal was predicted close to gauge corner on the high rail and on the top of the low rail. This can also help to identify which contacts are more susceptible to generating rail wear such as flange contacts on the former and severe tread contacts with high contact stresses on the latter were shown to be the main drivers for rail wear. 


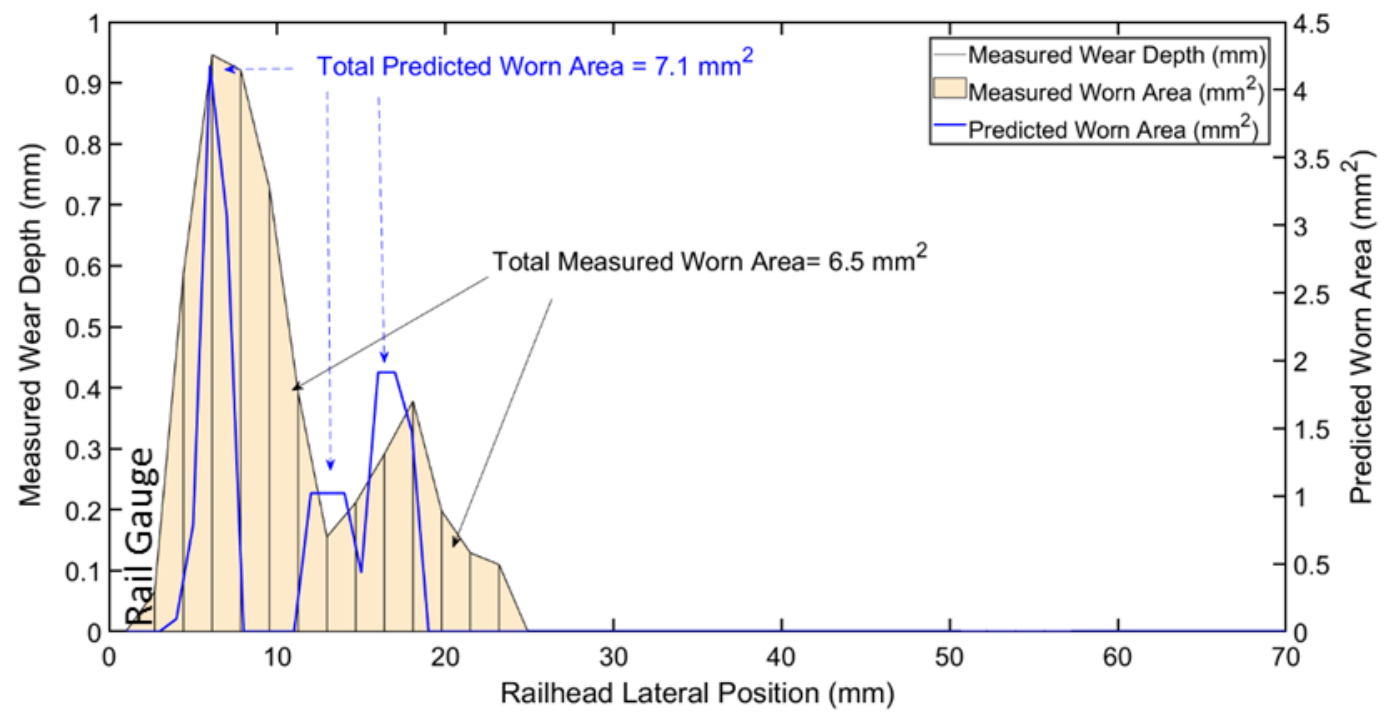

Figure 12: Comparison of MiniProf (depth) measurements and worn (area) predictions on the high rail (Days 300) site

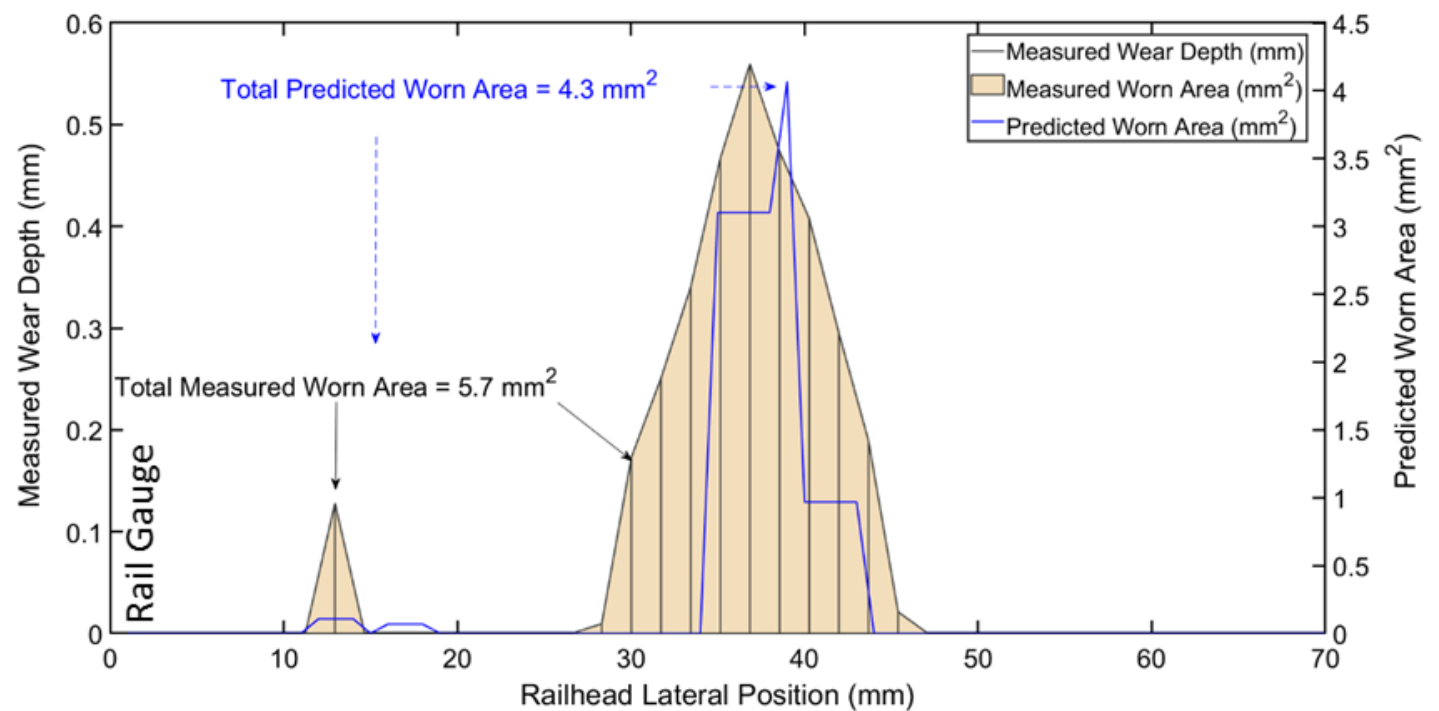

Figure 13: Comparison of MiniProf (depth) measurements and worn (area) predictions on the low rail (Days 300) site

Figure 14 shows a comparison of the predicted and measured worn areas for all the cases and highlights the variation from the linear 1:1 trend line. While rail locations are represented by the marker, the colour indicates the time period range following rail installation. Even though the majority of cases showed a good correlation, especially on the high and low rails of unchecked $(\mathrm{R}>200 \mathrm{~m})$ curved tracks, as they were close to the linear trend, the new method produced a number of under-and over-estimations.

The underestimations were particularly observed on BH type rails and tangent track sites. Although the wear predictions were relatively larger on $\mathrm{BH}$ type of rails due to its unconformal shape, the results were still insufficient to reach the actual measurements, as the sharp gauge corner radius limited the predicted wear on the gauge region. In addition, the relatively lower contact stresses on tangent track sites reduce the predicted worn areas.

The overestimations mainly occurred on checked curved tracks and sites with older rails. Owing to uncertainty in the actual check rail positions at the site conditions, the effect of both with and without check rails were considered in the simulations which resulted in substantially higher predictions than measurements at several locations. Additionally, the predictions were greater on older rails stemming 
from potential decay in ratchetting rates and steady-state wear regime. Under repetitive wheel passages, different types of shakedown responses take place. While some passages will exceed the shakedown limit and cause plastic deformation to accumulate, the other passages as well as the surface displacement resulting from this previous exceedance might affect the shakedown limit and hence, lead material to a reversion to a shakedown state or continue to increase ratchetting. Therefore, when the surface material is removed by wear, the material in the deeper layers has different plastic flow accumulation history which in turn will potentially reduce the ratchetting rate over time. Additionally, the wear rate can decrease after a certain time and reached steady state regime.

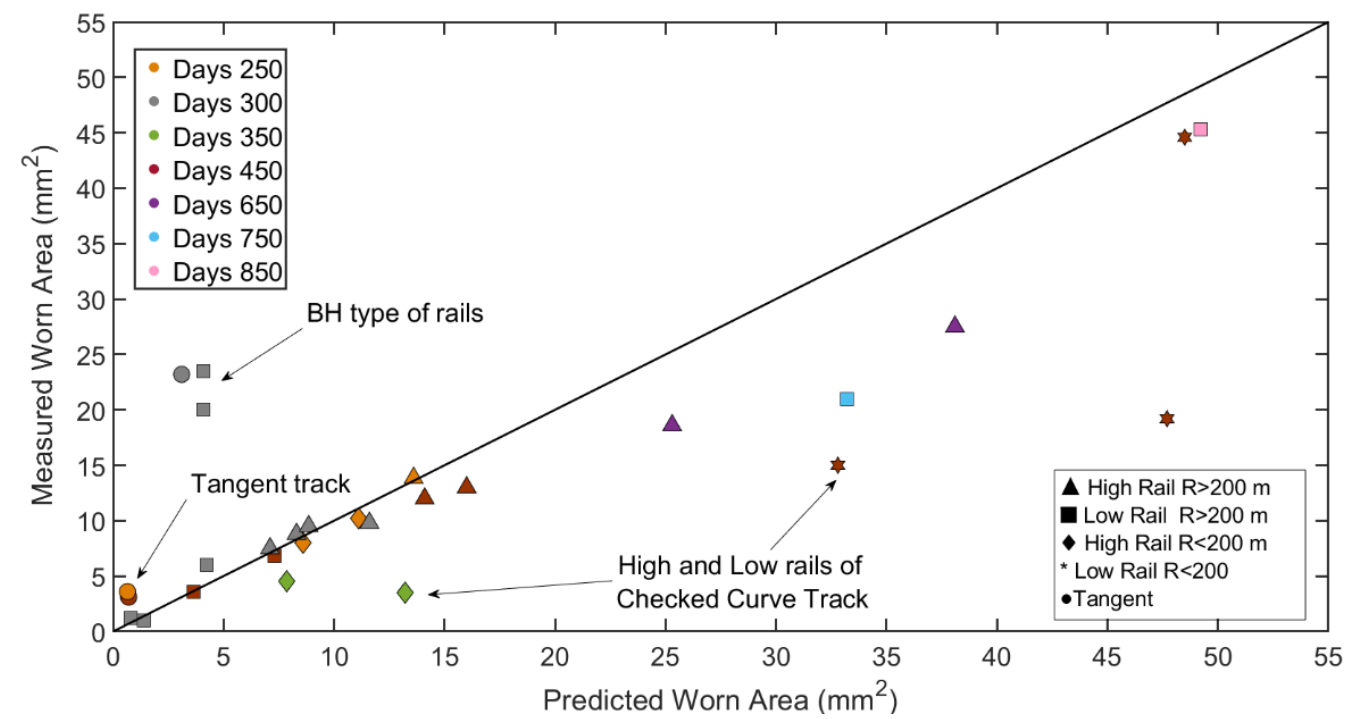

Figure 14: Comparison of predicted and measured worn areas for all cases

\subsection{RCF Damage Predictions}

The new RCF crack depth prediction model was both developed and validated using the MRX-RSCM rail inspection data. This system can detect both surface and sub-surface RCF damage with a maximum crack depth of $7 \mathrm{~mm}$ by measuring the changes in the flux strength induced by a magnet located in the device [51]. With the help of 19 sensors positioned $5 \mathrm{~mm}$ apart across the railhead and $2.5 \mathrm{~mm}$ longitudinal detection interval, a $5 \mathrm{~mm}$ x $2.5 \mathrm{~mm}$ damage map is generated on the railhead. Figure 15 presents the detector, its influence area on the railhead and example of measurement outputs. The surface damage map shows the damage severity based on the pre-defined colour scale where a dark blue colour demonstrates a light/minor damage, a red colour shows a more severe/deep damage. The crack depth diagram shows the maximum crack depths measured in $1 \mathrm{~m}$ interval.

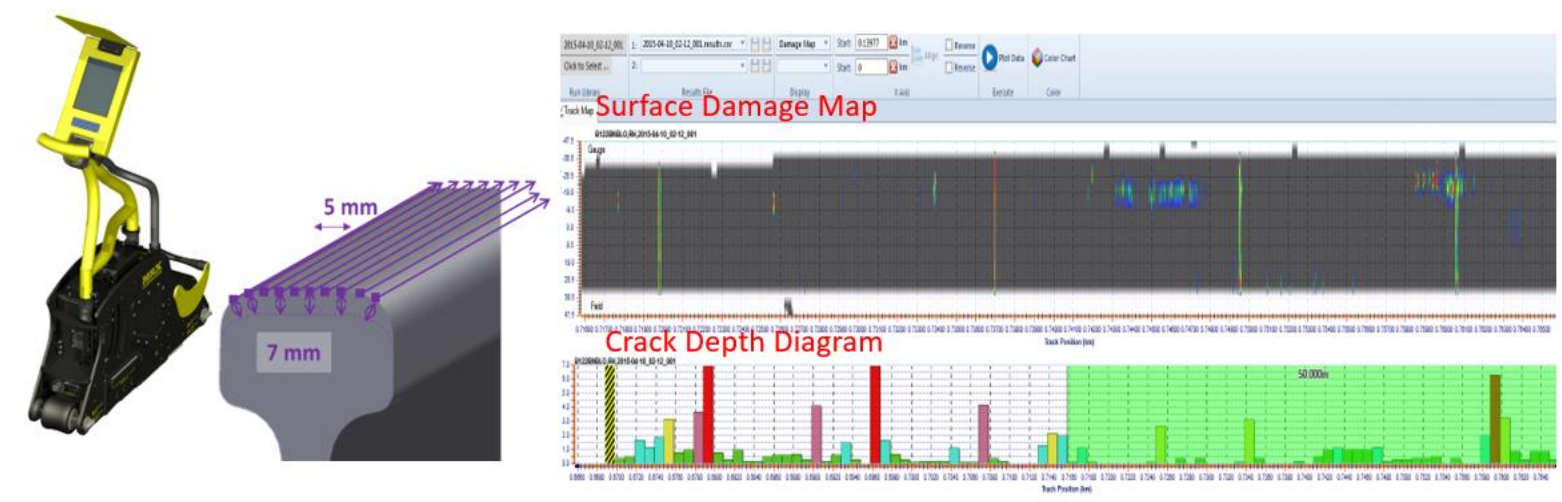

Figure 15: MRX-RSCM detector, its influence area over railhead and measurement outputs 
In the study, certain measures were taken in order to increase the reliability of MRX-RSCM data. For instance, the maximum crack depth was further post-processed and hence, evaluated in every $250 \mathrm{~mm}$ instead of $1000 \mathrm{~mm}$. In addition, the weld positions were used to assure that correct data aligning was implemented between consecutive measurements.

Since the wear is removing material from the rail surface and potentially shortening the depth of the cracks, the interaction of wear is taken into account in the RCF predictions. Thereby, the (net) RCF predictions reduced by the wear predictions were correlated with the MRX-RSCM measurements.

Figure 16 presents the comparisons between the predictions and two consecutive MRX-RSCM measurements on the high rail of the $440 \mathrm{~m}$ radius curved track on the Bakerloo line. As expected from the lower tonnage levels, the crack depths were relatively small and the new model succeeded to predict these smaller magnitudes. However, there were certain variations between predictions and measurements along the distance longitudinally and the spikes on both of the measurements cannot be predicted by the model. As the aim of the new model is to support the optimum maintenance strategy and to find the depth of material required to be removed by grinding which could be applicable to sites with various track geometries, these smaller variations were found to be satisfactory and beneficial in order not to remove unnecessary material. For instance, the further consideration of peak predictions such as $80^{\text {th }}$ percentile can be taken into account in grinding depths. 


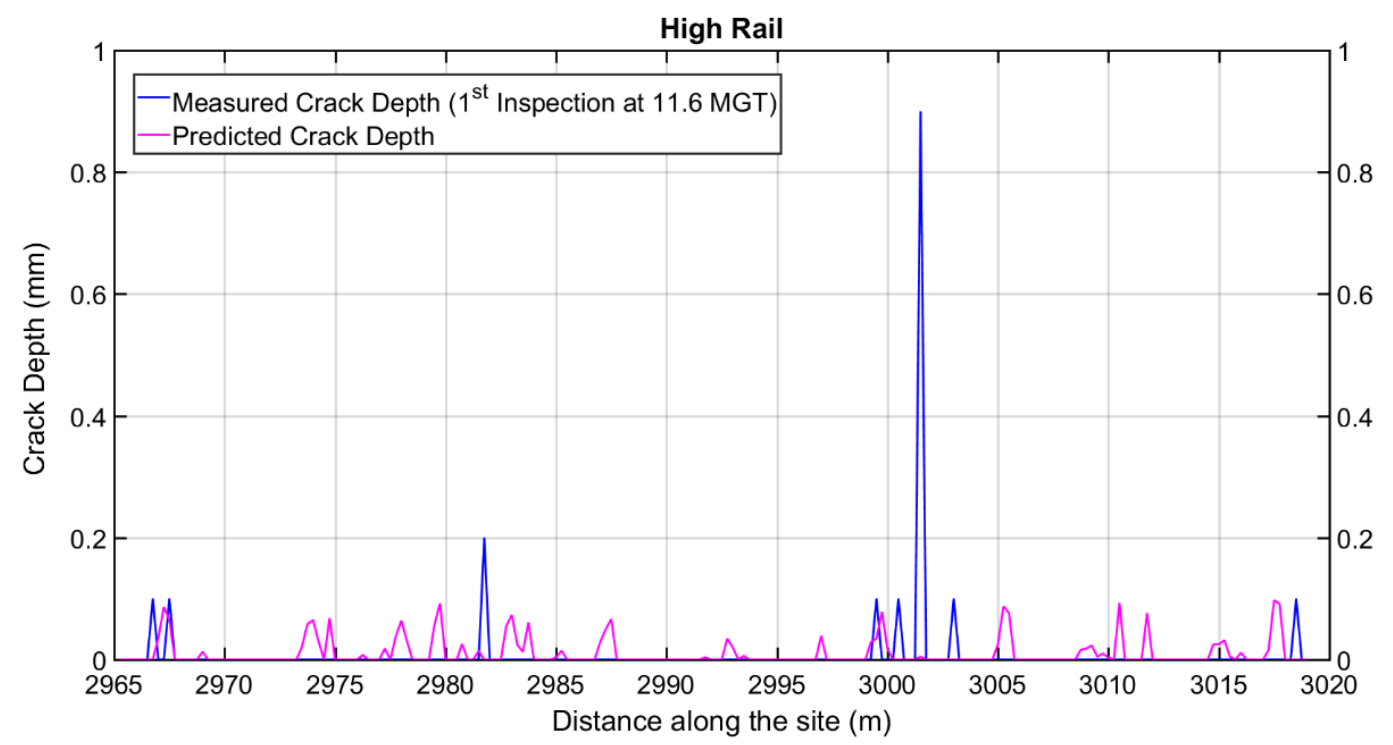

(a)

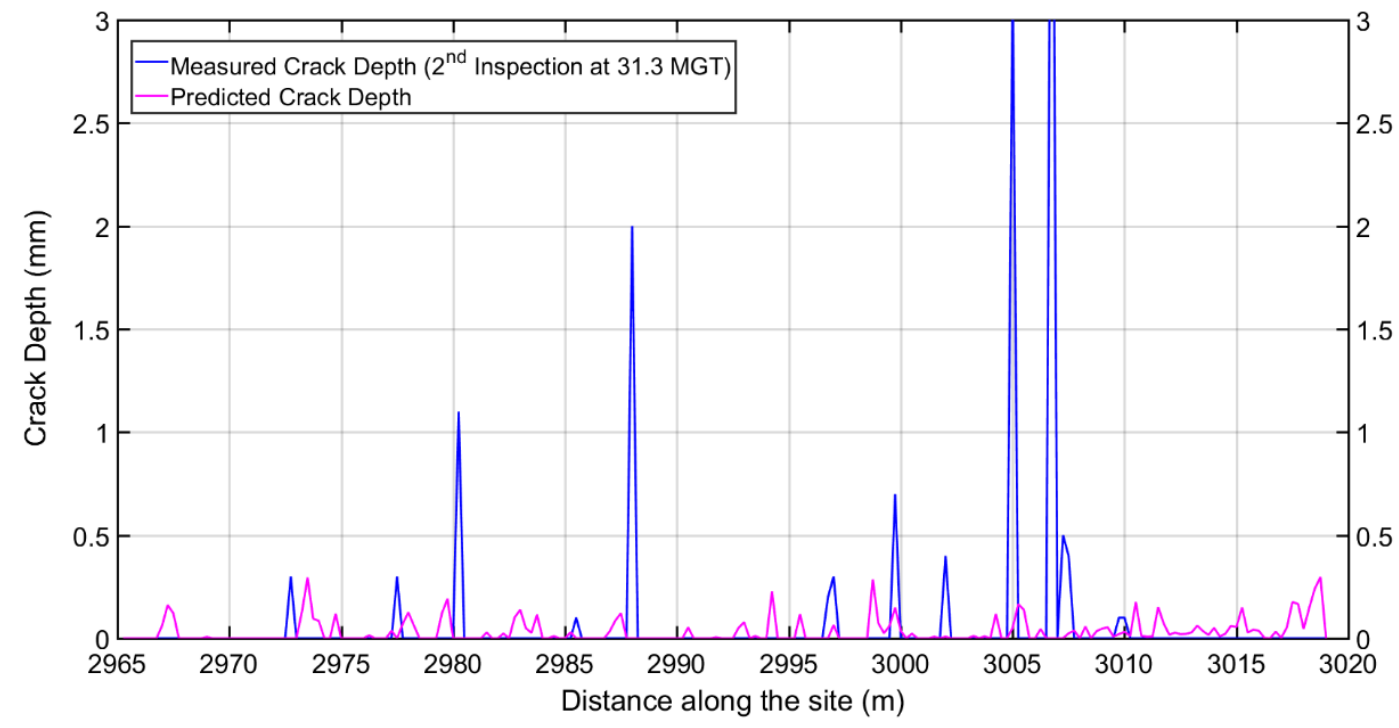

(b)

Figure 16: Comparison of RCF crack depth predictions with MRX_RSCM measurements and the differences from WLRM damage index on the high rail site - (a) $1^{\text {st }}$ inspection, 11.6 MGT and (b) $2^{\text {nd }}$ inspection, 31.3 MGT

Figure 17 presents the comparisons on the low $(\mathrm{BH})$ rail of the $280 \mathrm{~m}$ curved track of the Bakerloo line. Similar to high rail case, the differences between predictions and measurements were relatively small. But, some of the deep cracking measured in the first inspection reduced in the second inspection which caused the model to over-estimate. In addition, lower contact stresses may result in higher RCF predictions where the wear damage was underestimated on these $\mathrm{BH}$ type of rails.

Nonetheless, it should be pointed out that it is inevitable to observe certain differences between predictions and measurements, as various track sites including checked curved tracks with different rail profiles such as $\mathrm{BH}$ and FB rails were taken into account in the model development. 


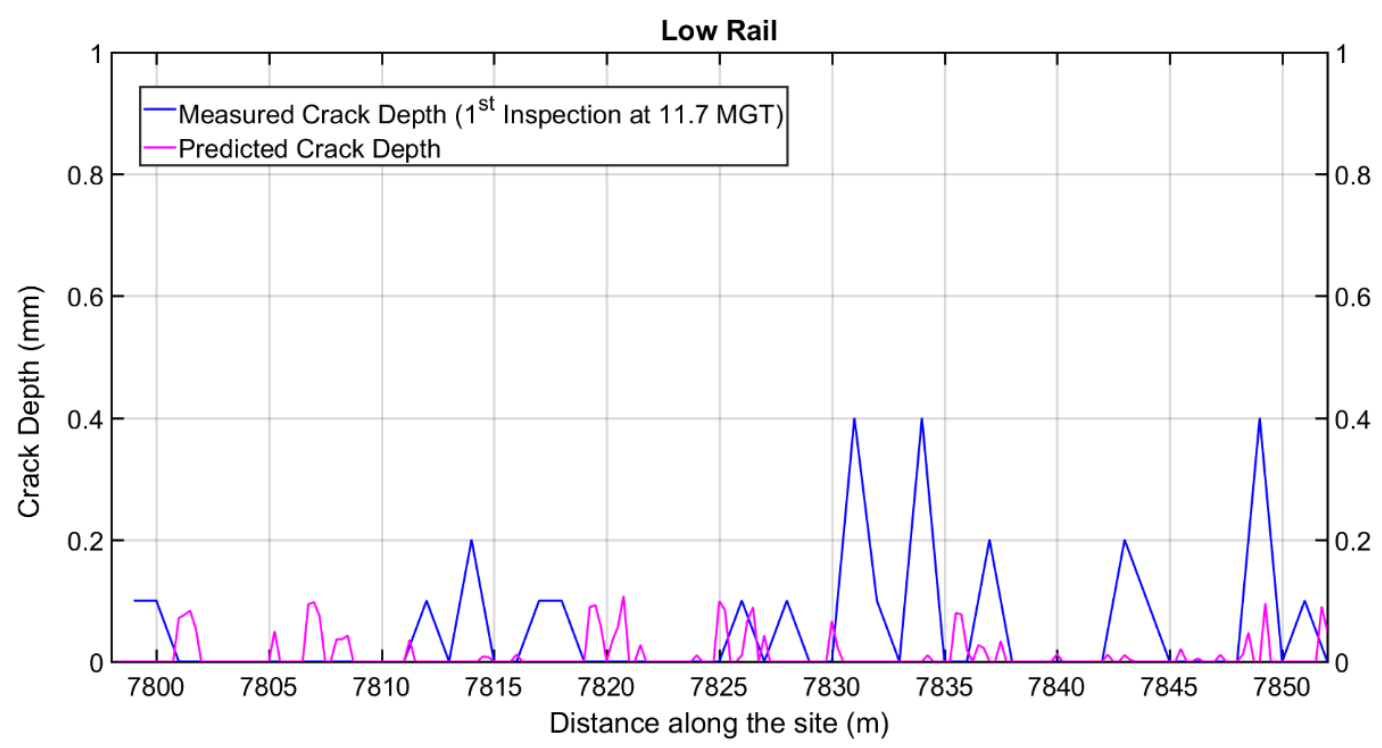

(a)

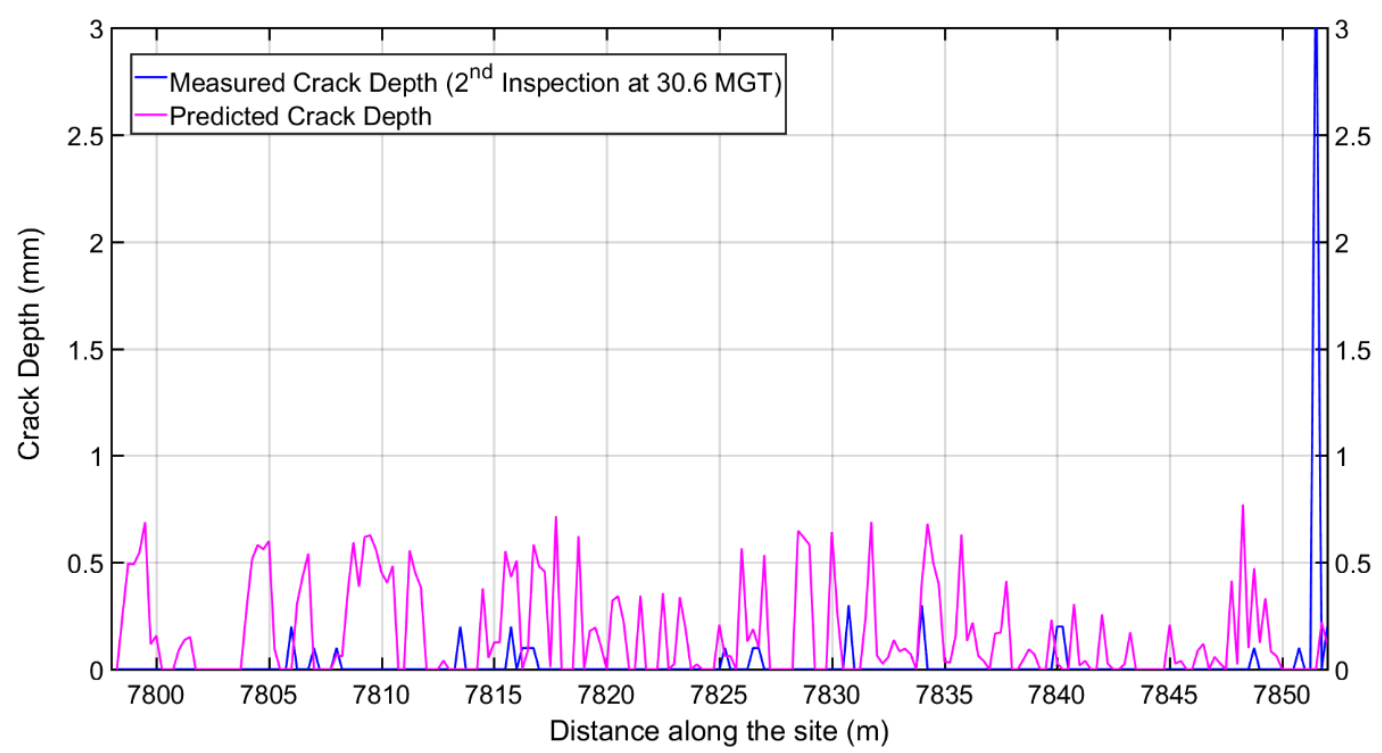

(b)

Figure 17: Comparison of RCF crack depth predictions with MRX_RSCM measurements and the differences from WLRM damage index on the low rail site - (a) $1^{\text {st }}$ inspection, 11.7 MGT and (b) $2^{\text {nd }}$ inspection, 30.6 MGT

To illustrate the location of the predicted and observed damage across the railhead, Figure 18 was prepared which presents the summation of crack depths along the length of the high and low rail sites. In spite of the fact that the crack depths vary along the sites, these plots can help to identify the most vulnerable regions on the railhead and which contacts were responsible. For instance, while the larger flange contact stresses gave rise to wear damage, the higher shear forces at tread contacts led to RCF initiation on the middle of the railhead in the first inspection. As the rail profile wears over time, a reduction in the flange contact stress results was observed and hence, cracks start to develop close to gauge corner indicated in the second inspection. On the low rail, the tread contacts may either remove the initiated cracks in this region or contribute to crack propagation close to the field side in the second inspection.

However, it can be also seen that the predicted lateral positions show some differences when compared to the field measurements. This difference was associated with changes in the gauge datum point 
between the Vampire and MRX-RSCM data and variations in rail profile shape generated between the first and second inspection.

The model could not demonstrate the plastic flow propagation towards field side, as observed in both the high and low rail sites. One of the previous studies which analysed the experiments for propagation of both of the damage types stated that although the propagation of wear was confined within the plastically deformed layer, the RCF cracks grew beyond this layer [52]. Therefore, while better agreement was obtained in the wear lateral predictions, the lateral RCF predictions of the model need to be improved.
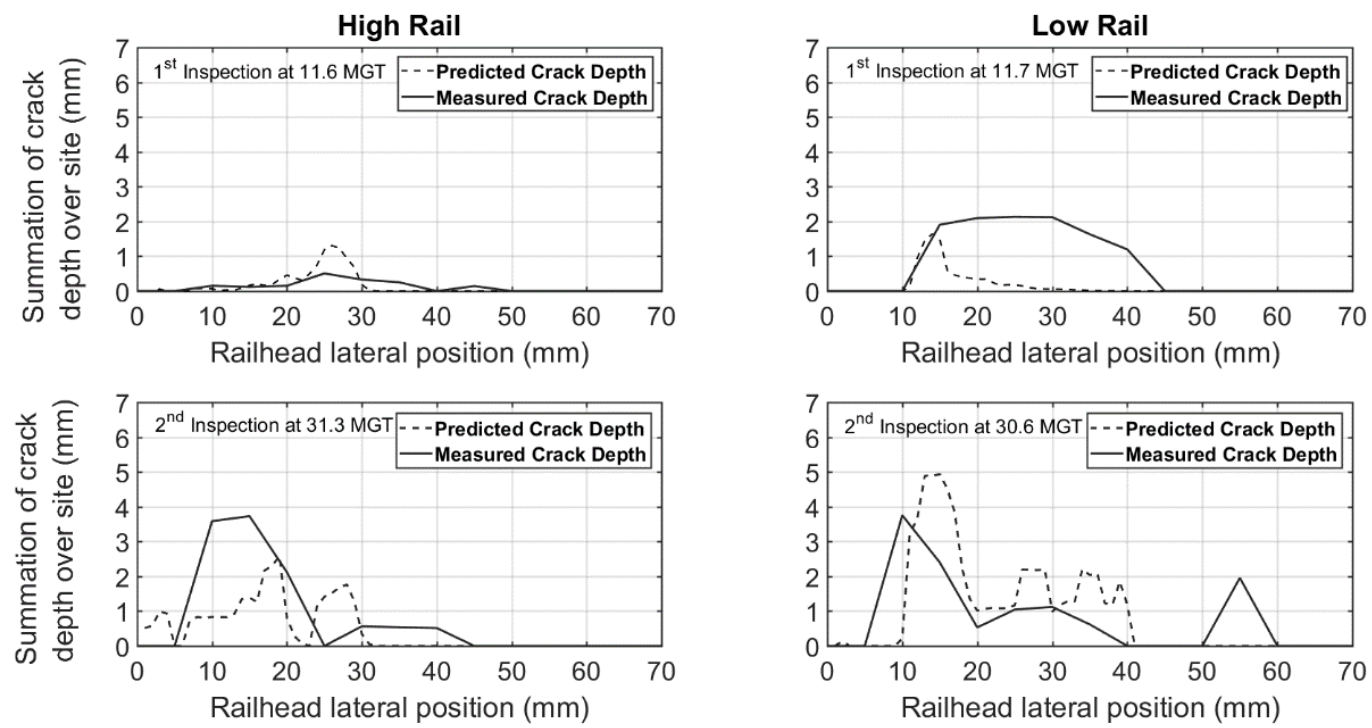

Figure 18: Comparison of accumulated RCF crack depth lateral positions between predictions and measurements

\subsection{Discussions}

The results from previous $\mathrm{T} \gamma$ and Shakedown Map predictions both in literature and from application on LUL have demonstrated that although good indications of sites susceptible to damage were provided, the severity of the predicted damage was over-and under-estimated under certain circumstances. Through comparison between sites with reported and no reported RCF defects, it is noted that certain parameters vary and hence a new combined Shakedown Map and T $\gamma$ approach was developed with the help of an iterative process.

In respect to wear predictions, the method provided relatively good correlations both in terms of severity and location (lateral) of the wear on the railhead. However, uncertainties in track characteristics on some sites resulted in differences between the prediction results and observed wear. For example; assumptions related to the position and flangeway clearances in check rails within the simulations resulted in over estimations. Predictions for rails on sites with a relatively older age produced certain inaccuracies stemming from several factors, including the use of the BRR wear curves developed from dry conditions and the decay in ratchetting rates caused by the changes in plastic deformation history in the deeper layers which might potentially cause reductions in wear rates. Although these changes could be better identified in the laboratory test results [50], it was unknown when they occur in real track conditions. Therefore, scaling factors have been implemented in the model to account for these uncertainties. It is suggested that wear curves with third-body materials should be considered in the future and the changes in wear levels should be monitored at a larger number of sites to further increase the accuracy of wear predictions. 
In respect to RCF predictions, a similar magnitude of damage was predicted with the developed model along with the changes in crack depths along the majority of the sites. The model results such as using peak values (or $80^{\text {th }}$ percentile) are thus believed to be suitable for finding the required depth of material which should be removed by grinding. It should be highlighted that it is inevitable to observe certain differences in these comparison plots since various track geometry conditions with different rail profiles such as BH and FB rails were considered in the model development and these were the optimum results when the model was applied to these different particular sites. Similarly, some discrepancies were also observed on the lateral location comparisons stemming from variations in rail profile shape and differences in the gauge datum point. In addition, changes in the deformed material microstructure and crack growth rate during these different phases should be also considered in future, as these influence the position and orientation of crack development. The use of a more comprehensive local contact model, such as non-Hertzian models with detailed calculation of creep force distributions over the contact patch, along with a higher number of worn wheel-rail profile will help to improve the accuracy of the predictions. Nonetheless, they provided the opportunity to identify which contacts were more responsible for the observed damage on rails.

Furthermore, it should be pointed out that the new approach presented in this paper was developed semi-empirically using a massive volume of field (crack depth) measurements from a metrounderground system. Therefore, in order to measure its applicability on different networks such as mainline and freight routes, further data and analysis are required from those sites.

\section{Conclusions}

To optimise the maintenance of the rail asset, it is important to combine data acquired from inspection and NDT techniques with accurate prediction of rail damage rates. This paper described the assumptions and limitations of the current rail damage models, from previous studies and their initial application on an underground-metro system. Variations in the model input parameters for predicting damage in sites with reported and no reported RCF damage was assessed and suggested further consideration in the prediction modelling.

The prediction model includes a combined Shakedown Map and T $\gamma$ approach. Instead of using visual surface crack conditions, crack depth measurements from NDT data, which are a key parameter in assessing the crack severity and maintenance planning was used in the development and validation of the new model. The prediction and validations were conducted using the consecutive crack measurements which allowed the changes in RCF damage propagation and its interaction with wear to be observed. The model was applied to several sites with various track characteristics. Through further validation, these models may help to support future maintenance planning and a move towards condition-based maintenance regime.

Future work will continue to study the monitoring records from the selected sites and compare with different sites on the LUL network. The use of more detailed modelling tools, such as an improved wheel-rail contact model will be also considered to further increase the accuracy of model predictions. In addition, the efficiency of this new approach in different operating environments such as mainline and freight routes can be tested when additional data from these networks are obtained.

\section{Acknowledgement}

The authors would like thank Rail Safety and Standard Boards (RSSB), UK for the funding of the research project and providing the $\mathrm{PhD}$ scholarship. In addition, thanks to London Underground for sharing the significant volume of field data and their collaboration during the project. 


\section{REFERENCES}

1. Zerbst U, Lundén R, Edel K-O, Smith RA. Introduction to the damage tolerance behaviour of railway rails-a review. Engineering fracture mechanics. 2009;76(17):2563-601.

2. Olofsson U, Zhu Y, Abbasi S, Lewis R, Lewis S. Tribology of the wheel-rail contact-aspects of wear, particle emission and adhesion. Vehicle System Dynamics. 2013;51(7):1091-120.

3. Donzella G, A. M, C. P. Competition between wear and rolling contact fatigue at the wheel-rail interface: some experimental evidence on rail steel. Proceedings of the Institution of Mechanical Engineers, Journal of Rail and Rapid Transit. 2009;Part F:223-31.

4. Fletcher $D$, Hyde $P$, Kapoor A. Modelling and full-scale trials to investigate fluid pressurisation of rolling contact fatigue cracks. Wear. 2008;265(9):1317-24.

5. Bogdański S, Brown M. Modelling the three-dimensional behaviour of shallow rolling contact fatigue cracks in rails. Wear. 2002;253(1):17-25.

6. Ringsberg J. Shear mode growth of short surface-breaking RCF cracks. Wear. 2005;258(7):95563.

7. Bogdański S, Lewicki P. 3D model of liquid entrapment mechanism for rolling contact fatigue cracks in rails. Wear. 2008;265(9):1356-62.

8. Van KD, Griveau B, editors. On a new multiaxial fatigue limit criterion: theory and application. ICBMFF2; 1989.

9. Jiang Y, Sehitoglu H. A model for rolling contact failure. Wear. 1999;224(1):38-49.

10. Anders Ekberga EK. Fatigue of railway wheels and rails under rolling contact and thermal loading-an overview. Wear. 2005;258:1288-300.

11. Larijani N, Brouzoulis J, Schilke M, Ekh M. The effect of anisotropy on crack propagation in pearlitic rail steel. Wear. 2014;314(1-2):57-68.

12. Trummer G, Marte C, Scheriau S, Dietmaier P, Sommitsch C, Six K. Modeling wear and rolling contact fatigue: Parametric study and experimental results. Wear. 2016;366-367:71-7.

13. Six K, Meierhofer A, Trummer G, Bernsteiner C, Marte C, Müller G, et al. Plasticity in wheelrail contact and its implications on vehicle-track interaction. Proceedings of the Institution of Mechanical Engineers, Part F: Journal of Rail and Rapid Transit. 2017;231(5):558-69.

14. Johnson KL. Plastic deformation in rolling contact: Springer; 2000.

15. Franklin F, Kapoor A. Modelling wear and crack initiation in rails. Proceedings of the Institution of Mechanical Engineers, Part F: Journal of rail and rapid transit. 2007;221(1):23-33.

16. Burstow M. Whole Life Rail Model application and development: Development of a rolling contact fatigue damage parameter 2003 October. Report No.: AEATR-ES-2003-832 Issue 1.

17. McEwen IJ, Harvey RF. Interpretation of Wheel/Rail Wear Numbers. 1986. Report No.: TMVDY-004.

18. Bolton PJ, Clayton P, McEwen IJ. Wear of Rail and Tire Steels Under Rolling/Sliding Conditions. ASLE TRANSACTIONS. 1982;25(1):17-24.

19. Burstow M. Whole life rail model application and development-Continued development of an RCF damage parameter. T115 project report, RSSB. 2004.

20. Burstow M, Fletcher D, Franklin F, Kapoor A. Management and Understanding of Rolling Contact Fatigue:WP1 Mechanisms of Crack Initiation. 2008.

21. Bevan A. Further Devolopment of the WLRM Damage Parameter 2011. Report No.: T775-01 project report.

22. Burstow M. Background to the Ty RCF damage function 2006.

23. Evans J, Lee T, Hon C. Optimising the wheel/rail interface on a modern urban rail system. Vehicle System Dynamics. 2008;46(S1):119-27.

24. Burstow M. Proposed new WLRM damage functions for alternative rail steels. 2009.

25. Hiensch M, Steenbergen MJW. Rolling Contact Fatigue on premium rail grades: Damage function development from field data. 2018;394:187-94. 
26. Garnham J, Fletcher D, Davis C, Franklin F. Visualization and modelling to understand rail rolling contact fatigue cracks in three dimensions. Proceedings of the Institution of Mechanical Engineers, Part F: Journal of Rail and Rapid Transit. 2011;225(2):165-78.

27. Innotrack. D4.1.4 Rail Degradation Algorithms. 2009. Report No.: Project no. TIP5- CT-20060314150.

28. Harvey RF, McEwen IJ. The Relationship Between Wear Number and Wheel/Rail Wear in the Laboratory and the Field. 1986. Report No.: TM-VDY-001.

29. Lewis R, Dwyer-Joyce RS, Olofsson U, Pombo J, Ambrósio J, Pereira M, et al. Mapping railway wheel material wear mechanisms and transitions. Proceedings of the Institution of Mechanical Engineers, Part F: Journal of Rail and Rapid Transit. 2010;224(3):125-37.

30. Jendel $T$, Berg $M$, Tidigare I, Farkost- och $f$, Kth. Prediction of Wheel Profile Wear: methodology and verification. Vehicle System Dynamics. 2002;37(sup1):502-13.

31. Hardwick C, Lewis R, Eadie DT. Wheel and rail wear-Understanding the effects of water and grease. Wear. 2014;314(1-2):198-204.

32. Ponter A, Hearle A, Johnson K. Application of the kinematical shakedown theorem to rolling and sliding point contacts. Journal of the Mechanics and Physics of Solids. 1985;33(4):339-62.

33. Ringsberg J. Life prediction of rolling contact fatigue crack initiation. International Journal of Fatigue. 2001;23(7):575-86.

34. Johnson KL. The strength of surfaces in rolling contact. Proceedings of the Institution of Mechanical Engineers, Part C: Mechanical Engineering Science. 1989;203(3):151-63.

35. Ayasse JB, Chollet H. Wheel-rail contact. In: Iwnicki S, editor. Handbook of railway vehicle dynamics2006. p. 86-120.

36. Dirks B, Enblom R. Prediction model for wheel profile wear and rolling contact fatigue. Wear. 2011;271(1):210-7.

37. Ponter A, Chen $\mathrm{H}$, Ciavarella M, Specchia G. Shakedown analyses for rolling and sliding contact problems. International Journal of Solids and Structures. 2006;43(14):4201-19.

38. Ekberg A, Åkesson B, Kabo E. Wheel/rail rolling contact fatigue-Probe, predict, prevent. Wear. 2014;314(1):2-12.

39. Kabo E, Ekberg A, Torstensson PT, Vernersson T. Rolling contact fatigue prediction for rails and comparisons with test rig results. Proceedings of the Institution of Mechanical Engineers, Part F: Journal of Rail and Rapid Transit. 2010;224(4):303-17.

40. Stichel S, Mohr H, Ågren J, Enblom R. Investigation of the risk for rolling contact fatigue on wheels of different passenger trains. Vehicle System Dynamics. 2008;46(1):317-27.

41. Jones $\mathrm{CP}$, Tyfour WR, Beynon JH, Kapoor A. The effect of strain hardening on shakedown limits of a pearlitic rail steel. 1997;211(2):131-40.

42. Boyacioglu P. Prediction of Rail Damage on Underground-Metro Lines 2018.

43. Boyacioglu P, Bevan A, Vickerstaff A. Prediction of RCF Damage on Underground Metro Lines. American Society of Civil Engineers (ASCE). 2017;ICRT 2017: Railway Development, Operations, and Maintenance.:207-25.

44. Boyacioglu P, Bevan A, Vickerstaff A, editors. Use of NDT Inspection Data to Improve Rail Damage Prediction Models. The 8th International Conference on Railway Engineering; 2018; London/UK: IET.

45. Olofsson U. 17 - Adhesion and friction modification. In: Lewis R, Olofsson U, editors. WheelRail Interface Handbook: Woodhead Publishing; 2009. p. 510-27.

46. Sinclair J, editor Friction modifiers, in "Vehicle track interaction: identifying and implementing solutions". IMechE Seminar, February 17th; 2004.

47. Eadie DT, Elvidge D, Oldknow K, Stock R, Pointner P, Kalousek J, et al. The effects of top of rail friction modifier on wear and rolling contact fatigue: Full-scale rail-wheel test rig evaluation, analysis and modelling. Wear. 2008;265(9):1222-30.

48. Schilke M. Degradation of Railway Rails from a Materials Point of View. Göteborg, Sweden: Chalmers University of Technology; 2013. 
49. Zhong W, Hu JJ, Shen P, Wang CY, Lius QY. Experimental investigation between rolling contact fatigue and wear of high-speed and heavy-haul railway and selection of rail material. Wear. 2011;271:2485-93.

50. Lewis R, Magel E, Wang W-J, Olofsson U, Lewis S, Slatter T, et al. Towards a standard approach for the wear testing of wheel and rail materials. Proceedings of the Institution of Mechanical Engineers, Part F: Journal of Rail and Rapid Transit. 2017;231(7):760-74.

51. MRX. Rail Surface Crack Measurement Manual. 2011.

52. Tyfour $W$, Beynon J. The effect of rolling direction reversal on the wear rate and wear mechanism of pearlitic rail steel. Tribology International. 1994;27(6):401-12. 